\title{
Homeostatic Feedback Modulates the Development of Two-State Patterned Activity in a Model Serotonin Motor Circuit in Caenorhabditis elegans
}

\author{
-Bhavya Ravi, ${ }^{1,2}$ Jessica Garcia, ${ }^{2}$ and ${ }^{\circledR}$ Kevin M. Collins ${ }^{1,2}$ \\ ${ }^{1}$ Neuroscience Program, University of Miami Miller School of Medicine, Miami, Florida 33136 and ${ }^{2}$ Department of Biology, University of Miami, \\ Coral Gables, Florida 33143
}

\begin{abstract}
Neuron activity accompanies synapse formation and maintenance, but how early circuit activity contributes to behavior development is not well understood. Here, we use the Caenorhabditis elegans egg-laying motor circuit as a model to understand how coordinated cell and circuit activity develops and drives a robust two-state behavior in adults. Using calcium imaging in behaving animals, we find the serotonergic hermaphrodite-specific neurons (HSNs) and vulval muscles show rhythmic calcium transients in L4 larvae before eggs are produced. HSN activity in L4 is tonic and lacks the alternating burst-firing/quiescent pattern seen in egg-laying adults. Vulval muscle activity in L4 is initially uncoordinated but becomes synchronous as the anterior and posterior muscle arms meet at HSN synaptic release sites. However, coordinated muscle activity does not require presynaptic HSN input. Using reversible silencing experiments, we show that neuronal and vulval muscle activity in L4 is not required for the onset of adult behavior. Instead, the accumulation of eggs in the adult uterus renders the muscles sensitive to HSN input. Sterilization or acute electrical silencing of the vulval muscles inhibits presynaptic HSN activity and reversal of muscle silencing triggers a homeostatic increase in HSN activity and egg release that maintains $\sim 12-15$ eggs in the uterus. Feedback of egg accumulation depends upon the vulval muscle postsynaptic terminus, suggesting that a retrograde signal sustains HSN synaptic activity and egg release. Our results show that egg-laying behavior in C. elegans is driven by a homeostat that scales serotonin motor neuron activity in response to postsynaptic muscle feedback.
\end{abstract}

Key words: behavior; C. elegans; calcium; circuit; developmental biology; serotonin

Significance Statement

The functional importance of early, spontaneous neuron activity in synapse and circuit development is not well understood. Here, we show in the nematode Caenorhabditis elegans that the serotonergic hermaphrodite-specific neurons (HSNs) and postsynaptic vulval muscles show activity during circuit development, well before the onset of adult behavior. Surprisingly, early activity is not required for circuit development or the onset of adult behavior and the circuit remains unable to drive egg laying until fertilized embryos are deposited into the uterus. Egg accumulation potentiates vulval muscle excitability, but ultimately acts to promote burst firing in the presynaptic HSNs which results in egg laying. Our results suggest that mechanosensory feedback acts at three distinct steps to initiate, sustain, and terminate $C$. elegans egg-laying circuit activity and behavior.

\section{Introduction}

Developing neural circuits in the cortex, hippocampus, cerebellum, retina, and spinal cord show spontaneous neural activity
(Wong et al., 1995; Garaschuk et al., 1998, 2000; Watt et al., 2009; Warp et al., 2012). In contrast, mature neural circuits show coordinated patterns of activity required to drive efficient behaviors. Activity-dependent mechanisms have been shown to play key roles during development in vertebrate neural circuits ( $\mathrm{Gu}$ et

Scheetz for technical assistance and help with strain construction and James Baker, Julia Dallman, Laura Bianchi, Peter Larsson, Stephen Roper, and members of the Collins laboratory for helpful discussions and feedback. The authors declare no competing financial interests.

Correspondence should be addressed to Kevin M. Collins, Department of Biology, University of Miami, 1301 Memorial Drive, Coral Gables, FL 33143. E-mail: kevin.collins@miami.edu.

DOI:10.1523/JNEUROSCI.3658-17.2018

Copyright $\odot 2018$ the authors $\quad 0270-6474 / 18 / 386283-16 \$ 15.00 / 0$ 
al., 1994; Gu and Spitzer, 1995; Jarecki and Keshishian, 1995; Borodinsky et al., 2004; Hanson et al., 2008), but the complexity of such circuits poses limitations in terms of understanding how developmental events, neurotransmitter specification, and sensory signals act together to promote the transition from immature to mature patterns of circuit activity. Genetically tractable invertebrate model organisms, such as the nematode Caenorhabditis elegans, have simple neural circuits and are amenable to powerful experimental approaches allowing us to investigate how activity in neural circuits is shaped during development.

The C. elegans egg-laying circuit is a well characterized neural circuit that drives a two-state behavior in adult animals with $\sim 20$ min inactive periods punctuated by $\sim 2$ min active states during which $\sim 4-6$ eggs are laid (Waggoner et al., 1998). The egg-laying circuit comprises two serotonergic hermaphrodite-specific neurons (HSNs) that promote the active state (Waggoner et al., 1998; Emtage et al., 2012), three locomotion motor neurons (VA7, VB6, and VD7), and six cholinergic ventral C neurons (VC1-6), all of which synapse onto a set of vulval muscles whose rhythmic activity drives either weak twitching or the release of eggs from the uterus in phase with locomotion (White et al., 1986; Collins and Koelle, 2013; Collins et al., 2016). Four uv1 neuroendocrine cells connect the vulval canal to the uterus, which holds embryos until they are laid. HSN, VC, uv1, and vulval muscle development occurs during the early to mid-L4 larval stages and requires interactions with the developing vulval epithelium, but not the other cells in the circuit (Newman et al., 1996; Burdine et al., 1998; Colavita and Tessier-Lavigne, 2003; Shen et al., 2004).

During egg laying, serotonin released from the HSNs signals through vulval muscle receptors (Carnell et al., 2005; Dempsey et al., 2005; Hobson et al., 2006; Hapiak et al., 2009), likely increasing the excitability of the muscles so that rhythmic input from cholinergic motor neurons can drive vulval muscle contractions (White et al., 1986; Collins and Koelle, 2013; Collins et al., 2016). We have shown previously that $\mathrm{HSN} \mathrm{Ca}^{2+}$ transients occur more frequently during the active state, but the factors that promote this timely "feed-forward" increase in HSN activity remain poorly understood. The cholinergic VCs show rhythmic $\mathrm{Ca}^{2+}$ transients coincident with vulval muscle contractions during the active state, although whether VC activity drives contraction itself or instead acts to modulate HSN signaling is still not clear (Bany et al., 2003; Zhang et al., 2008; Zang et al., 2017). The uv1 cells, mechanically deformed by the passage of eggs through the vulva, release tyramine and neuropeptides that signal extrasynaptically to inhibit HSN activity (Collins et al., 2016; Banerjee et al., 2017). Because each cell in the circuit develops independently in juveniles, how this circuit goes on to develop the robust pattern of coordinated activity seen in adults remains unclear.

We show here that the presynaptic HSN motor neurons and the postsynaptic vulval muscles are active during the late L4 larval stage, well before egg production and the onset of adult egglaying behavior. We did not observe activity in the VC neurons or uv1 neuroendocrine cells until behavioral onset. The adult circuit remains in a non-functional state until receiving feedback of eggs in the uterus. This egg-laying homeostat requires the vm 2 muscle arms and muscle activity, which we show promotes HSN burst firing that maintains the active state. Together, our data reveal how cell activity patterns that emerge during circuit development are modulated by sensory feedback that determines when and for how long to drive behavior.

\section{Materials and Methods}

\section{Nematode culture and developmental staging}

C. elegans hermaphrodites were maintained at $20^{\circ} \mathrm{C}$ on Nematode Growth Medium (NGM) agar plates with E. coli OP50 as a source of food as described previously (Brenner, 1974). Animals were staged and categorized based on the morphology of the vulva as described previously (Mok et al., 2015). For assays involving young adults, animals were age matched based on the timing of completion of the L4 larval molt. All assays involving adult animals were performed using age-matched adult hermaphrodites $20-40 \mathrm{~h}$ past the late L4 stage.

\section{Plasmid and strain construction}

\section{Calcium reporter transgenes}

Vulval muscle $\mathrm{Ca}^{2+}$. To visualize vulval muscle $\mathrm{Ca}^{2+}$ activity in adult animals, we used LX1918 vsIs164 [unc-103e::GCaMP5::unc-54 3'UTR + unc-103e::mCherry::unc-54 3'UTR + lin-15(+)] lite-1(ce314) lin15(n765ts) $X$ strain as described previously (Collins et al., 2016). In this strain, GCaMP5G (Akerboom et al., 2013) and mCherry are expressed from the unc-103e promoter (Collins and Koelle, 2013). The unc-103e promoter is only weakly expressed in vulval muscles during the L4 stages. To visualize vulval muscle activity in L4 animals, we expressed GCaMP5G and mCherry from the ceh-24 promoter (Harfe and Fire, 1998). An $\sim 2.8 \mathrm{kB}$ DNA fragment upstream of the ceh-24 start site was amplified from genomic DNA by PCR using the following oligonucleotides: 5'-GCG GCA TGC AAC GAG CCA TCC TAT ATC GGT GGT CCT CCG- $3^{\prime}$ and $5^{\prime}$-CAT CCC GGG TTC CAA GGC AGA GAG CTG CTG-3'. This DNA fragment was ligated into pKMC257 (mCherry) and pKMC274 (GCaMP5G) from which the unc-103e promoter sequences were excised to generate pBR3 and pBR4, respectively. pBR3 $(20 \mathrm{ng} / \mu \mathrm{l})$ and pBR4 $(80 \mathrm{ng} / \mu \mathrm{l})$ were injected into LX1832 lite-1(ce314) lin15(n765ts) $X$ along with the pLI5EK rescue plasmid (50 ng/ $\mu$ l) (Clark et al., 1994). The extrachromosomal transgene produced was integrated by irradiation with UV light after treatment with trimethylpsoralen (UV/ TMP), creating two independent transgenes, keyIs 12 and keyIs13, which were then backcrossed to the LX1832 parental line six times to generate the strains MIA51 and MIA53. Strain MIA51 keyIs12 [ceh-24::GCaMP5:: unc-54 3'UTR + ceh-24::mCherry::unc-54 3'UTR + lin-15(+)] IV; lite1(ce314) lin-15 (n765ts) X was subsequently used for $\mathrm{Ca}^{2+}$ imaging. We noted repulsion between keyIs 12 and wzIs30 IV, a transgene that expresses Channelrhodopsin-2::YFP in HSN from the egl-6 promoter (Emtage et al., 2012), suggesting both were linked to chromosome IV. As a result, we crossed MIA53 keyIs13 [ceh-24::GCaMP5::unc-54 3'UTR + ceh-24:: mCherry::unc-54 3'UTR + lin-15(+)]; lite-1(ce314) lin-15(n765ts)X with LX1836 wzIs30 IV; lite-1(ce314) lin-15(n765ts) X, generating MIA88 which was used to activate HSN neurons and record vulval muscle $\mathrm{Ca}^{2+}$ in L4 animals. In the case of young adults ( 3.5 and $6.5 \mathrm{~h}$ after molt) and 24-h-old adults, strain LX1932 wzIs30 IV; vsIs164 lite-1(ce314) lin15(n765ts) $X$ was used as described previously (Collins et al., 2016).

$\mathrm{HSN} \mathrm{Ca}^{2+}$. To visualize HSN Ca ${ }^{2+}$ activity in $\mathrm{L} 4$ and adult animals, we used the LX2004 vsIs183 [nlp-3::GCaMP5::nlp-3 3'UTR + nlp-3:: $m$ Cherry::nlp-3 3'UTR + lin-15(+)] lite-1(ce314) lin-15(n765ts) X strain expressing GCaMP5G and mCherry from the $n l p-3$ promoter as described previously (Collins et al., 2016). To visualize $\mathrm{HSN} \mathrm{Ca}^{2+}$ activity in lin-12 (wy750) mutant animals lacking postsynaptic vm2 vulval muscle arms, we crossed MIA194 lin-12(wy750) III with LX2004 vsIs183 lite1(ce314) lin-15(n765ts) X to generate MIA196 lin-12(wy750) III; vsIs183 $X$ lite-1(ce314) lin-15 (n765ts) X. To visualize HSN Ca ${ }^{2+}$ activity in $g l p-$ 1 (or178ts) mutant animals, we crossed EU552 glp-1(or178ts) III with LX2004 vsIs183 lite-1(ce314) lin-15(n765ts) X to generate MIA219 glp1(or178ts) III; vsIs183 lite-1(ce314) lin-15(n765ts) X.

Histamine-gated chloride channel ( $\mathrm{His} \mathrm{Cl}$ )-expressing transgenes Vulval muscle $\mathrm{HisCl}$. To produce a vulval-muscle-specific HisCl transgene, coding sequences for mCherry in pBR3 were replaced with that for $\mathrm{HisCl}$. First, an EagI restriction site (3' of the mCherry encoding sequence) was changed to a NotI site using QuikChange site-directed mutagenesis to generate pBR5. The $\sim 1.2 \mathrm{kB}$ DNA fragment encoding the HisCl channel was amplified from pNP403 (Pokala et al., 2014) using the 
following oligonucleotides: 5'-GCG GCT AGC GTA GAA AAA ATG CAA AGC CCA ACT AGC AAA TTG G-3' and 5'-GTG GCG GCC GCT TAT CAT AGG AAC GTT GTC-3' ${ }^{\prime}$, cut with NheI/NotI, and ligated into pBR5 to generate pBR7. pBR7 $(80 \mathrm{ng} / \mu \mathrm{l})$ was injected into LX1832 along with pLI5EK $(50 \mathrm{ng} / \mu \mathrm{l})$. One line bearing an extrachromosomal transgene was integrated with UV/TMP and six independent integrants (keyIs14 to keyIs19) were recovered. Four of these were then backcrossed to the LX1832 parental line six times to generate strains MIA68, MIA69, MIA70, and MIA71. All four strains were used for behavioral assays in adult animals to test the effect of vulval muscle silencing on egg laying (see Fig. 4B). MIA71 keyIs19 [ceh-24::HisCl::unc-54 3'UTR + lin-15(+)]; lite-1(ce314) lin-15(n765ts) $X$ strain was used to study the effect of acute silencing of early activity on egg-laying behavior (see Fig. $4 C$ ). To visualize HSN Ca ${ }^{2+}$ activity after vulval muscle silencing, we crossed MIA71 with LX2004 to generate strain MIA80 keyIs19; vsIs183 lite-1(ce314) lin15(n765ts) X.

$\mathrm{HSN} \mathrm{HisCl}$. The $\sim 1.2 \mathrm{kB}$ DNA fragment encoding the HisCl channel was amplified from pNP403 using the following oligonucleotides: $5^{\prime}$ GCG GCT AGC GTA GAA AAA ATG CAA AGC CCA ACT AGC AAA TTG G-3' and 5' -GCG GAG CTC TTA TCA TAG GAA CGT TGT CCA ATA GAC AAT A-3'. The amplicon was digested with NheI/SacI and ligated into similarly cut pSF169 (pegl-6::mCre; Flavell et al., 2013) to generate pBR10. To follow expression in HSN, mCherry was amplified using the following oligonucleotides: 5'-GCG GCT AGC GTA GAA AAA ATG GTC TCA AAG GGT-3' and 5'-GCG GAG CTC TCA GAT TTA CTT ATA CAA TTC ATC CAT G-3'. This amplicon was digested with NheI/SacI and ligated into pSF169 to generate pBR12. pBR10 (HisCl; 5 $\mathrm{ng} / \mu \mathrm{l})$ and pBR12 (mCherry; $10 \mathrm{ng} / \mu \mathrm{l})$ were injected into LX1832 lite1(ce314) lin-15(n765ts) along with pLI5EK ( $50 \mathrm{ng} / \mu \mathrm{l})$. The extrachromosomal transgene produced was integrated with UV/TMP, creating three independent integrants (keyIs20, keyIs21, and keyIs22). The resulting animals were backcrossed to the LX1832 parental line six times to generate strains MIA115, MIA116, and MIA117. The MIA116 strain had a low incidence of HSN developmental defects and was used subsequently for behavioral assays.

All neuron HisCl. pNP403 was injected into LX1832 lite-1(ce314) lin$15(n 765 t s)$ animals at $50 \mathrm{ng} / \mu \mathrm{l}$ along with pLI5EK ( $50 \mathrm{ng} / \mu \mathrm{l})$ to produce strain MIA60 carrying extrachromosomal transgene keyEx16 [tag-168:: HisCl::SL2::GFP + lin15(+)]. NonMuv, lin-15(+) animals with strong GFP expression in the HSNs and other neurons were selected before behavioral silencing assays. All animals showed histamine-dependent paralysis that recovered after washout.

Transgenic reporters of circuit development and morphology Vulval muscle morphology. To visualize vulval muscle development at the L4 stages, we injected pBR3 [pceh-24::mCherry] $(80 \mathrm{ng} / \mu \mathrm{l})$ along with a coinjection marker pCFJ90 (10 ng/ $\mu$ l) into TV201 wyIs22 [punc-86:: GFP::RAB-3 + podr-2::dsRed] (Patel et al., 2006) to generate an extrachromosomal transgene, keyEx42. To visualize adult vulval muscle morphology, we used the LX1918 vsIs164 [unc-103e::GCaMP5::unc-54 $3^{\prime} U T R+$ unc-103e::mCherry::unc-54 3'UTR + lin-15(+)] lite-1(ce314) lin-15(n765ts) X strain (Collins et al., 2016). To visualize the expression of the ser-4 gene, we used the strain AQ570 [ijIs570] (Tsalik and Hobert, 2003; Gürel et al., 2012).

HSN morphology. We used the LX2004 strain expressing mCherry from the $n l p-3$ promoter to visualize HSN morphology at L4 stages as well as in adults. To visualize GFP::RAB-3 synaptic localization in HSNs during development, the wyIs22 transgene was used (Patel et al., 2006).

Whole circuit morphology (HSN, VC, and uv1 cells). A $\sim 3.2 \mathrm{kB}$ DNA fragment upstream of the ida-1 start site (Cai et al., 2004) was cloned using the following oligonucleotides: 5' -GCG GCA TGC CCT GCC TGT GCC AAC TTA CCT- $3^{\prime}$ and $5^{\prime}$-CAT CCC GGG GCG GAT GAC ACA GAG ATG CGG-3'. The DNA fragment was digested with SphI/XmaI and ligated into pKMC257 and pKMC274 to generate plasmids pBR1 and pBR2. pBR1 $(20 \mathrm{ng} / \mu \mathrm{l})$ and pBR2 $(80 \mathrm{ng} / \mu \mathrm{l})$ were coinjected into LX1832 along with pLI5EK ( $50 \mathrm{ng} / \mu \mathrm{l})$. The extrachromosomal transgene produced was integrated with UV/TMP, creating four independent integrants keyIs 8 to keyIs11, which were then backcrossed to the LX1832 parental line six times. MIA49 keyIs11 [ida-1::GCaMP5::unc-543'UTR +
ida-1::mCherry::unc-54 3'UTR + lin-15(+)]; lite-1(ce314) lin-15 (n765ts) $X$ was used subsequently to visualize whole-circuit morphology.

\section{Fluorescence imaging}

$3 D$ confocal microscopy. To visualize the morphological development of the egg-laying system, L4s and age-matched adults were immobilized using $10 \mathrm{~mm}$ muscimol on $4 \%$ agarose pads and covered with \#1 coverslips. Two-channel confocal $Z$-stacks (along with a bright-field channel) using a pinhole opening of 1 Airy unit $(0.921-\mu \mathrm{m}$-thick optical sections, 16-bit images) were obtained with an inverted Leica TCS SP5 confocal microscope with a $63 \times$ Water Apochromat objective [1.2 numerical aperture (NA)]. GFP and mCherry fluorescence were excited using the 488 and $561 \mathrm{~nm}$ laser lines, respectively. Images were analyzed in Volocity 6.3.1 (PerkinElmer) and FIJI (Schindelin et al., 2012).

Ratiometric $\mathrm{Ca}^{2+}$ imaging. Ratiometric $\mathrm{Ca}^{2+}$ recordings were performed on freely behaving animals mounted between a glass coverslip and chunk of NGM agar as described previously (Collins and Koelle, 2013; Li et al., 2013; Collins et al., 2016; Ravi et al., 2018). Recordings were collected on an inverted Leica TCS SP5 confocal microscope using the $8 \mathrm{kHz}$ resonant scanner at $\sim 20 \mathrm{fps}$ at $256 \times 256$ pixel resolution, 12-bit depth, and $\geq 2 \times$ digital zoom using a $20 \times$ Apochromat objective (0.7 NA) with the pinhole opened to $\sim 20 \mu \mathrm{m}$. GCaMP5G and mCherry fluorescence was excited using the 488 and $561 \mathrm{~nm}$ laser lines, respectively. L4 animals at the relevant stages of vulval development were identified based on vulval morphology (Mok et al., 2015). Adult recordings were performed $24 \mathrm{~h}$ after the late L4 stage. Young adults (3.5-6.5 h) were staged after cuticle shedding at the L4 to adult molt. After staging, animals were allowed to adapt for $\sim 30$ min before imaging. During imaging, the stage and focus were adjusted manually to keep the relevant cell/presynapse in view and in focus.

Ratiometric analysis (GCaMP5:mCherry) for all $\mathrm{Ca}^{2+}$ recordings was performed after background subtraction using Volocity 6.3.1 as described previously (Collins et al., 2016; Ravi et al., 2018). The egg-laying active state was operationally defined as the period $1 \mathrm{~min}$ before the first egg-laying event and ending $1 \mathrm{~min}$ after the last (in the case of a typical active phase in which 3-4 eggs are laid in quick succession). However, for cases in which two egg-laying events were apart by $>60 \mathrm{~s}$, peaks were considered to be in separate active phases and transients between these were considered to be from the inactive state.

Ratiometric $\mathrm{Ca}^{2+}$ comparisons with different reporters and developmental stages. To facilitate comparisons of $\Delta \mathrm{R} / \mathrm{R}$ between different reporters at different developmental stages, particularly during periods of elevated $\mathrm{Ca}^{2+}$ activity, HSN recordings in which baseline GCaMP5/mCherry fluorescence ratio values were between 0.2 and 0.3 were selected for the analysis, whereas vulval muscle recordings with GCaMP5/mCherry ratio values between 0.1 and 0.2 were chosen ( $\geq 80 \%$ of recordings). Because HSN Ca ${ }^{2+}$ transient amplitude did not change significantly across developmental stages or in mutant or drug treatment backgrounds, our analyses focused on $\mathrm{HSN} \mathrm{Ca}^{2+}$ transient frequency. To test whether vulval muscle $\mathrm{Ca}^{2+}$ transient amplitudes recorded using different transgenes were suitable for quantitative comparisons, we measured the average GCaMP5:mCherry fluorescence ratio from two 15 by $15 \mu \mathrm{m}$ regions of interest (ROIs) from the anterior and posterior vulval muscles under identical imaging conditions (data not shown). The ROIs were positioned to ensure maximal coverage of the muscle cell area. We found that resting GCaMP5:mCherry ratios ( $\pm 95 \%$ confidence intervals) bearing either the ceh-24 (keyIs12) or unc-103e (vsIs164) vulval muscle $\mathrm{Ca}^{2+}$ reporter transgenes were not statistically different at the developmental stages under comparison in Figure 3H [L4.7-8 (ceh-24): $1.055 \pm 0.027$; L4.9 (ceh-24): $1.055 \pm 0.061$; adult (unc-103e): $1.15 \pm 0.064 ; n \geq 10$ animals measured per developmental stage]. The coordination of vulval muscle contraction was determined as described previously ( $\mathrm{Li}$ et al., 2013).

Ether-a-Go-Go Related Gene (ERG) expression analysis. To measure ERG (unc-103e) expression in the vulval muscles during development in staged LX1918 L4.7-8 and L4.9 larvae and $24 \mathrm{~h}$ adults, we used imaging conditions identical to those used to measure mCherry fluorescence through a $20 \times$ Plan Apochromat objective (0.8 NA) using a Zeiss Axio 
Observer microscope onto a Hamamatsu ORCA Flash 4.0 V2 sCMOS sensor after excitation with a $590 \mathrm{~nm}$ LED (Zeiss Colibri.2). After import into Volocity, two $15 \times 15 \mu \mathrm{m}$ ROIs were placed on the anterior and posterior vulval muscles and the mCherry fluorescence of the two objects was averaged. A control ROI placed outside of the animal was used for background subtraction.

\section{Behavior assays and microscopy}

Optogenetics and defecation behavior assays. Channelrhodopsin-2 (ChR2)-expressing strains were maintained on OP50 with or without all-trans retinal (ATR) $(0.4 \mathrm{~mm})$. ChR2 was activated during $\mathrm{Ca}^{2+}$ imaging experiments with the same continuous laser light used to excite GCaMP5 fluorescence.

Acute silencing experiments using $\mathrm{HisCl}$. For acute silencing assays, NGM plates containing $10 \mathrm{~mm}$ histamine were prepared and used as described previously (Pokala et al., 2014). For adult behavioral assays, HisCl-expressing strains were staged as late L4s with histamine treatment and behavior assays performed $24 \mathrm{~h}$ later. For L4 activity silencing, L4.7 animals were placed on NGM plates with or without $10 \mathrm{~mm}$ histamine and monitored to determine when the animals completed the L4 molt. Each animal was then transferred to a new seeded plate (lacking histamine) and the time for each animal to lay its first egg was recorded.

Animal sterilization. Animals were sterilized using floxuridine (FUDR) as follows. First, $100 \mu \mathrm{l}$ of $10 \mathrm{mg} / \mathrm{ml}$ FUDR was applied to OP50-seeded NGM plates. Late L4 animals were then staged onto the FUDR plates and the treated adults were imaged $24 \mathrm{~h}$ later. MIA219 $g l p-1$ (or178ts) III; vsIs183 lite-1 (ce314) lin-15(n765ts) $X$ animals were sterilized during embryogenesis as described previously (Fujiwara et al., 2016). L1-L2 animals were shifted to $25^{\circ} \mathrm{C}$ and returned to $15^{\circ} \mathrm{C}$ after $24 \mathrm{~h}$. Late $\mathrm{L} 4$ animals were then staged and grown at $15^{\circ} \mathrm{C}$ and imaged $24 \mathrm{~h}$ later.

\section{Experimental design and statistical analysis}

Sample sizes for behavioral assays followed previous studies (Chase et al., 2004; Collins and Koelle, 2013; Collins et al., 2016). No explicit power analysis was performed before the study. Statistical analysis was performed using Prism 6 (GraphPad). $\mathrm{Ca}^{2+}$ transient peak amplitudes, widths, and intertransient intervals were pooled from multiple animals (typically $\sim 10$ animals per genotype/condition per experiment). No animals or data were excluded except as indicated above to facilitate comparisons of $\mathrm{Ca}^{2+}$ transient amplitudes between different development stages and reporters. Individual $p$-values are indicated in each figure legend and all tests were corrected for multiple comparisons (Bonferroni's for ANOVA; Dunn's for Kruskal-Wallis).

\section{Results}

\section{Asynchronous presynaptic and postsynaptic development in} the

\section{C. elegans egg-laying behavior circuit}

We have described previously the function of cell activity in the adult egg-laying behavior circuit and how developmental mutations affect circuit activity and adult behavior (Collins and Koelle, 2013; Li et al., 2013; Collins et al., 2016). Because development of the cells in the circuit is known to be complete by the end of the L4 stage ( $\mathrm{Li}$ and Chalfie, 1990), we wanted to determine the relationship between circuit development and the emergence of cell activity as the animals mature from juveniles into egg-laying adults. We exploited the stereotyped morphology of the developing primary and secondary vulval epithelial cells in the fourth (final) larval stage to define discrete half-hour stages of development until the L4 adult molt (Fig. 1A-F) as described previously (Mok et al., 2015). We observed NLP-3 neuropeptide promoter expression in HSNs of late L4 animals (Fig. $1 G-I$ ), showing that L4.7-8 HSNs have specified a transmitter phenotype. Consistent with L4.7-8 HSN being functional, the presynaptic marker GFP::RAB-3 expressed from the unc-86 promoter showed clear punctate localization in HSN at synaptic sites at these stages (Fig. $1 J-L$ ), confirming previous observations with light microscopy and serial electron microscopy reconstruction that HSN development is complete by L4.7-8 (Shen and Bargmann, 2003; Shen et al., 2004; Adler et al., 2006; Patel et al., 2006).

Unlike HSNs, we found the postsynaptic vulval muscles completed their morphological development during the L4.9 stage, just before the L4 molt. We expressed mCherry in the vulval muscles from the ceh-24 promoter (Harfe and Fire, 1998) and found that the vm 1 and vm 2 vulval muscles were still developing at the L4.7-8 stage (Fig. 1M). After lumen collapse at the L4.9 stage, the tips of the vm 1 muscles extended ventrally to the lips of the vulva and the anterior and posterior vm2 muscle arms extended laterally along the junction between the primary and secondary vulval epithelial cells (Fig. $1 N$ ), making contact with each other at the HSN (and VC) synaptic release sites that continues in adults (Fig. 1O). Previous work has shown that mutations that disrupt LIN-12/Notch signaling perturb development of the vm2 muscle arms in late L4 animals (Li et al., 2013), a time when we observed vm 2 muscle arm extension.

Vulval muscles express multiple serotonin receptors that mediate their response to HSN input (Carnell et al., 2005; Dempsey et al., 2005; Hobson et al., 2006; Hapiak et al., 2009). To look at the developmental expression pattern of one such serotonin receptor, we examined a transgenic reporter line expressing GFP under the $s e r-4 b$ gene promoter (Tsalik and Hobert, 2003; Gürel et al., 2012). As shown in Figure 1, $P$ and $Q$, we observed strong GFP expression in VulF and VulE primary and VulD secondary epithelial cells. The ser- $4 b$ promoter also drove weak GFP expression in the vm2 muscles in L4.7-9 and this was elevated in adults (Fig. 1P-R). Serial EM reconstruction has shown that HSN makes transient synapses onto the vulval epithelial cells in developing L4 animals and the expression of a serotonin receptor in these cells and the vm 2 muscles during this period suggests that they have specified a receptor phenotype (Shen et al., 2004). Last, we wanted to determine whether the VC motor neurons and uv1 neuroendocrine cells had completed their development in late L4 animals. To visualize HSN, VC, and the uv1 neuroendocrine cells simultaneously, we expressed mCherry from the ida-1 promoter, a gene expressed in a subset of peptidergic cells, including those in the egg-laying circuit (Cai et al., 2004). We observed mCherry expression in all three cell types in L4.7-8 animals, consistent with their development of a peptidergic phenotype in late L4 animals (Fig. $1 S-U$ ). As expected, HSN and VC presynaptic termini assembled at the junction between the primary and secondary vulval epithelial cells in L4.7-8. The uv1 cells were positioned laterally to the HSN/VC synaptic regions and extended dorsal processes around the primary vulval epithelial cells (Fig. 1S-U). These results indicate that the morphological development and peptidergic expression phenotype of the HSN, VC, and uv1 cells is largely complete by L4.7-8 stage. In contrast, vulval muscle morphological development is completed in the L4.9 stage when the vm2 muscle arms reach each other and the HSN and the VC presynaptic boutons and begin to express the serotonin receptor SER-4b.

\section{HSNs switch from tonic activity in juveniles to burst firing in egg-laying adults}

We next wanted to determine whether the HSNs show activity as they develop and how that activity compares to that seen in egglaying adults. To follow HSN activity, we expressed the $\mathrm{Ca}^{2+}$ reporter GCaMP5 along with mCherry in HSN using the $n l p-3$ promoter and performed ratiometric $\mathrm{Ca}^{2+}$ imaging in freely behaving animals as described previously (Collins et al., 2016). 


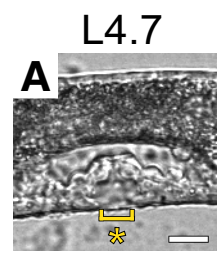

Time (h): 0

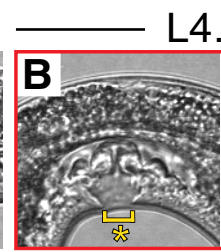

0.5

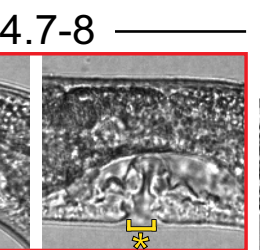

1

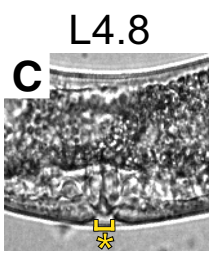

1.5

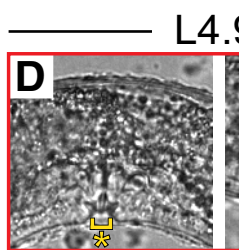

2
4.9

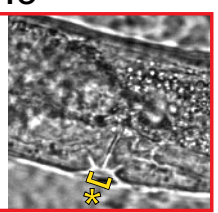

2.5

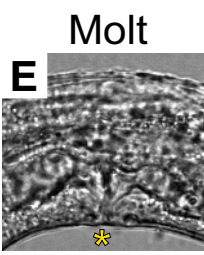

3

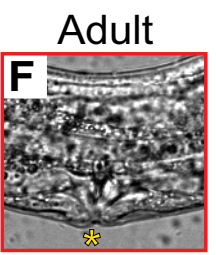

3.5

Developmental

stage: L4.7-8
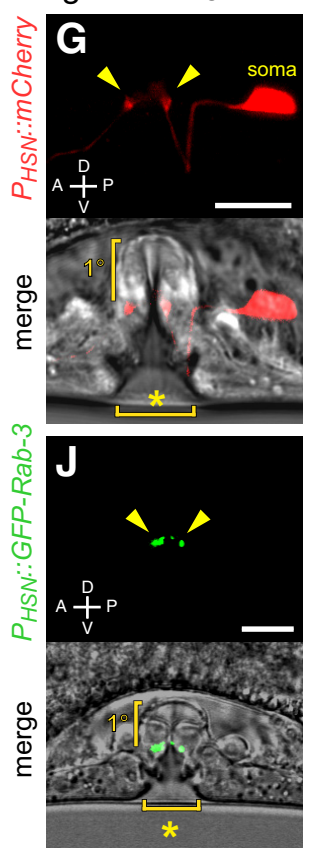

L4.9
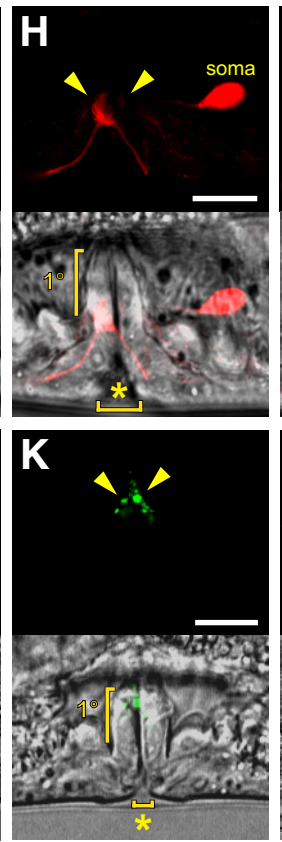

Adult
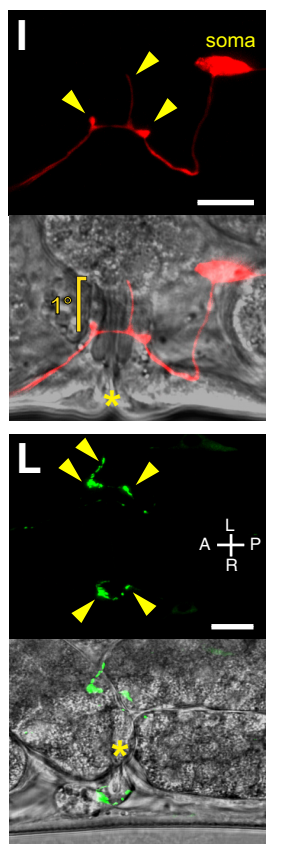

L4.7-8
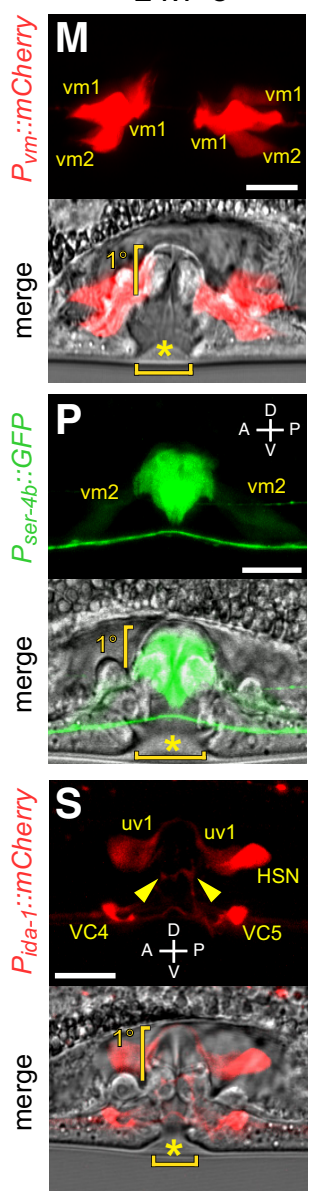

L4.9
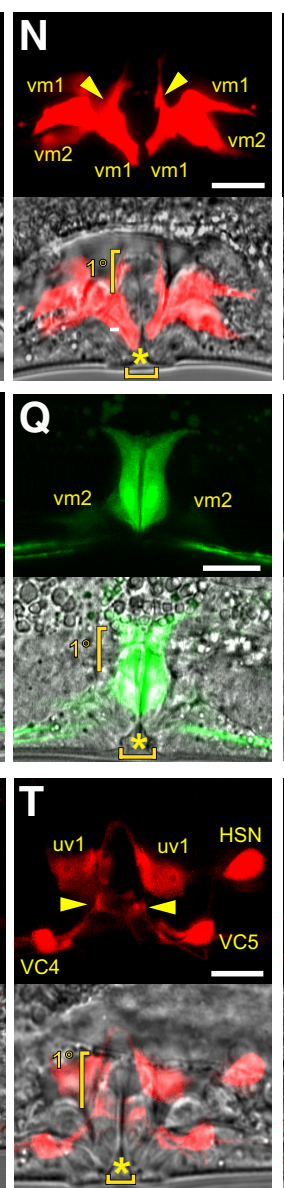

Adult
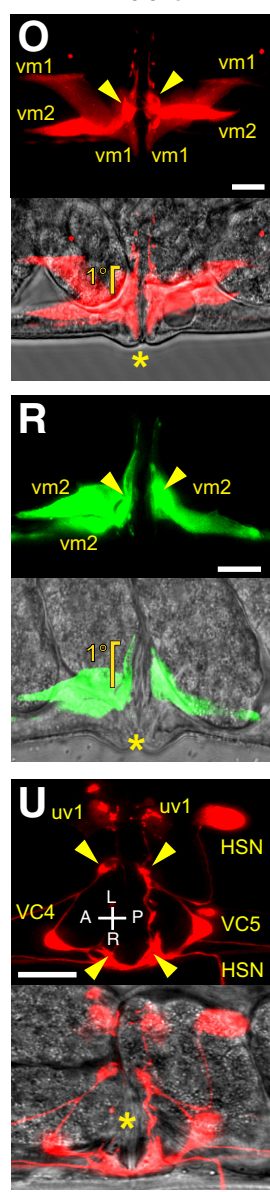

Figure 1. Morphological development of the C. elegans egg-laying circuit. $A-F$, Representative images of vulval morphology at late $L 4$ stages: $(\boldsymbol{A}) L 4.7,(\boldsymbol{B}) L 4.7-8$, (C) L4.8, (D) L4.9, (E) molt, and $(\boldsymbol{F})$ young adult. $\mathbf{G}-\boldsymbol{I}$, Morphology of HSN labeled with $\mathrm{mCherry}($ top) and the vulva (bottom) in $L 4.7-8(\boldsymbol{G})$ and $L 4.9(\boldsymbol{H})$ larval stages and in adults $(\boldsymbol{I})$. $\boldsymbol{J}-\boldsymbol{L}$, Morphology of HSN synapses labeled with GFP::RAB-3 (top) and the vulva (bottom) in $L 4.7-8(\boldsymbol{J})$ and $L 4.9(\boldsymbol{K})$ larval stages and in adults ( $\boldsymbol{L})$. $\boldsymbol{M}-\mathbf{0}$, Morphology of vm 1 and vm2 vulval muscles labeled with $\mathrm{mCherry}$ (top) and the vulva (bottom) in $L 4.7-8(\boldsymbol{M})$ and $L 4.9(\boldsymbol{N})$ larval stages and in adults $(\boldsymbol{O}) . \boldsymbol{P}-\boldsymbol{R}$, Developmental expression of ser-4 from a GFP transcriptional reporter (top) at the $L 4.7-8(\boldsymbol{P})$ and $L 4.9(\boldsymbol{Q})$ larval stages and in adults $(\boldsymbol{R})$ and the vulva (bottom). $\boldsymbol{S}-\boldsymbol{U}$, Morphology of HSN, VC4, VC5, and the uv1 neuroendocrine cells labeled with $\mathrm{mCherry}$ (top) and the vulva (bottom) in $L 4.7-8(\boldsymbol{S})$ and $L 4.9(\boldsymbol{T})$ larval stages and in adults $(\boldsymbol{U})$ visualized using the ida-1 promoter. Arrowheads in all images indicate the location of presynaptic boutons or postsynaptic vm2 muscle arms. Scale bar, $10 \mu \mathrm{m}$. Anterior is at left and ventral is at bottom unless indicated otherwise. Asterisks indicate the position of the developing or completed vulval opening. Vertical half-brackets indicate the approximate position of primary $\left(1^{\circ}\right)$ vulval epithelial cells and horizontal bracket indicates progress of vulval lumen collapse at each larval stage.

Starting at the L4.7-8 larval stage, we observed rhythmic $\mathrm{Ca}^{2+}$ activity in both HSN presynaptic termini and in the soma (Fig. $2 A, B$ ). During the L4.9 larval stage, when animals exhibited behavioral features of the developmentally timed L4 quiescence (Raizen et al., 2008), rhythmic $\mathrm{Ca}^{2+}$ activity in the HSNs slowed (Fig. 2B, Movie 1). The tonic HSN activity that we observed in juveniles (Fig. 2B, Movie 2) differed from the alternating, twostate pattern seen previously in adult animals, in which periods of infrequent activity are interrupted by bouts of HSN burst firing that drive the egg-laying active state (Collins et al., 2016). We quantitated changes in $\mathrm{HSN} \mathrm{Ca}^{2+}$ transient peak amplitude and frequency during the different developmental stages and behavior states. We found no significant differences in $\mathrm{HSN} \mathrm{Ca}^{2+}$ transient amplitude (Fig. 2C), but we did observe significant changes in frequency. The median intertransient interval in L4.7-8 animals was $\sim 34 \mathrm{~s}$ and this interval increased to $\sim 60 \mathrm{~s}$ as animals reached the L4.9 stage (Fig. 2D). The reduction of HSN transient frequency seen in L4.9 animals resembled the egg-laying inactive state. However, none of the developmental stages recapitulated the "burst" $\mathrm{Ca}^{2+}$ activity with $<20$ s intertransient intervals seen during the egg-laying active state (Fig. $2 D$ ). Together, these results indicate that the HSNs show tonic $\mathrm{Ca}^{2+}$ activity after their 
A
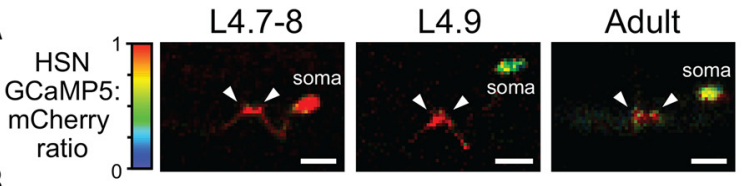

$\underline{60 \mathrm{~s}}$

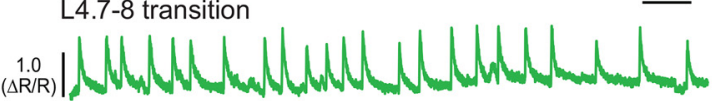
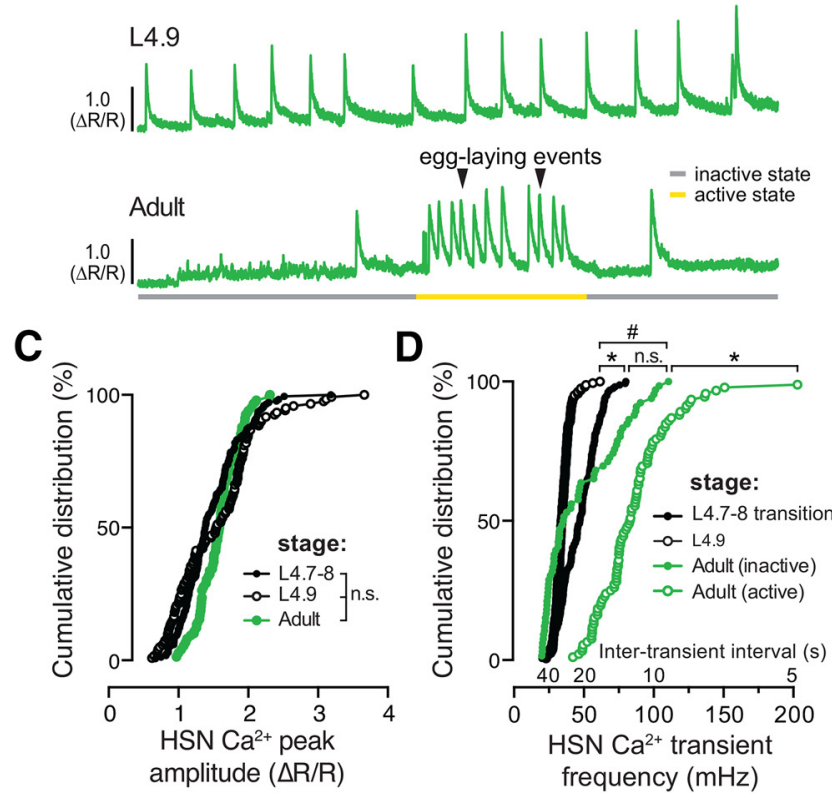

Figure 2. HSN neurons show tonic $\mathrm{Ca}^{2+}$ activity during the late $\mathrm{L} 4$ stage and burst firing during the egg-laying active state. $\boldsymbol{A}$, Representative images of the intensity-modulated GCaMP5:mCherry fluorescence ratio during HSN Ca ${ }^{2+}$ transients in L4.7-8 and L4.9 larval stages and in adults. White arrowheads show $\mathrm{Ca}^{2+}$ activity localized to the anterior and posterior presynaptic boutons. Scale bar, $10 \mu \mathrm{m}$. Anterior is at left and ventral is at bottom. See also Movies 1 and 2. B, Representative GCaMP5:mCherry ratio traces $(\Delta R / R)$ of HSN Ca ${ }^{2+}$ activity in L4.7-8 (top), L4.9 (middle), and in adult (bottom) animals. Adults show distinct active (yellow) and inactive (gray) egg-laying behavior states. Black arrowheads indicate egg-laying events. $\boldsymbol{C}$, Cumulative distributions of HSN Ca ${ }^{2+}$ peak amplitudes in L4.7-8 (filled black circles), L4.9 (open black circles), and adults (filled green circles). n.s. indicates $p>0.0809$ (one-way ANOVA). D, Cumulative distribution plots of instantaneous HSN Ca ${ }^{2+}$ transient frequencies (and intertransient intervals) from L4.7-8 (filled black circles) and L4.9 (open black circles) animals and from adult egg-laying inactive (filled green circles) and active (green open circles) states. ${ }^{*} p<0.0001 ; \# p=0.0283 ;$ n.s. indicates $p=0.1831$ (Kruskal-Wallis test).

morphological development is complete. HSN activity then switches into distinct inactive and active states as animals become egg-laying adults.

The onset of $\mathrm{Ca}^{2+}$ activity in the HSN neurons during the late L4 stage coincided with changes in animal locomotion, pharyngeal pumping, and defecation behaviors that accompany the L4 lethargus (Raizen et al., 2008). Previous published work has shown that there is an increase in animal locomotion in adult animals around egg-laying active states driven by serotonin signaling from HSN onto AVF (Hardaker et al., 2001). Loss of HSN neurons or serotonin signaling from HSN reduces reversals and increases forward locomotion and exploratory behavior (Flavell et al., 2013). To understand whether the tonic HSN activity seen in juveniles was associated with locomotor arousal, we analyzed movement in L4.9 animals 10 s before and after each $\mathrm{HSN} \mathrm{Ca}^{2+}$ transient. Approximately one-third of L4.9 HSN transients failed to show any movement before or after the transient $(35 \pm 7 \%$ ) and the remaining HSN transients were approximately evenly split between those that showed movements before (30 $\pm 7 \%$ ),

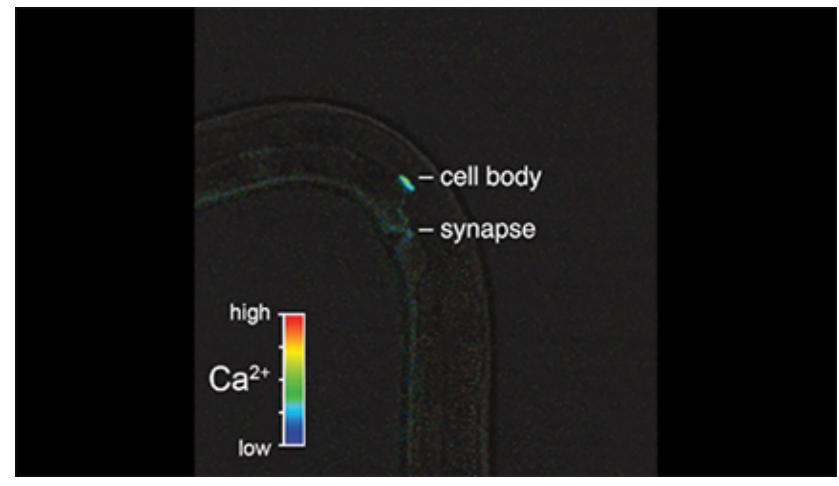

Movie 1. Ratio recording of a $\mathrm{HSN} \mathrm{Ca}^{2+}$ transient at the L4.9 larval stage. High $\mathrm{Ca}^{2+}$ is indicated in red and low calcium is in blue. The HSN cell body and presynaptic terminal are indicated. Head is at bottom and tail is at left.
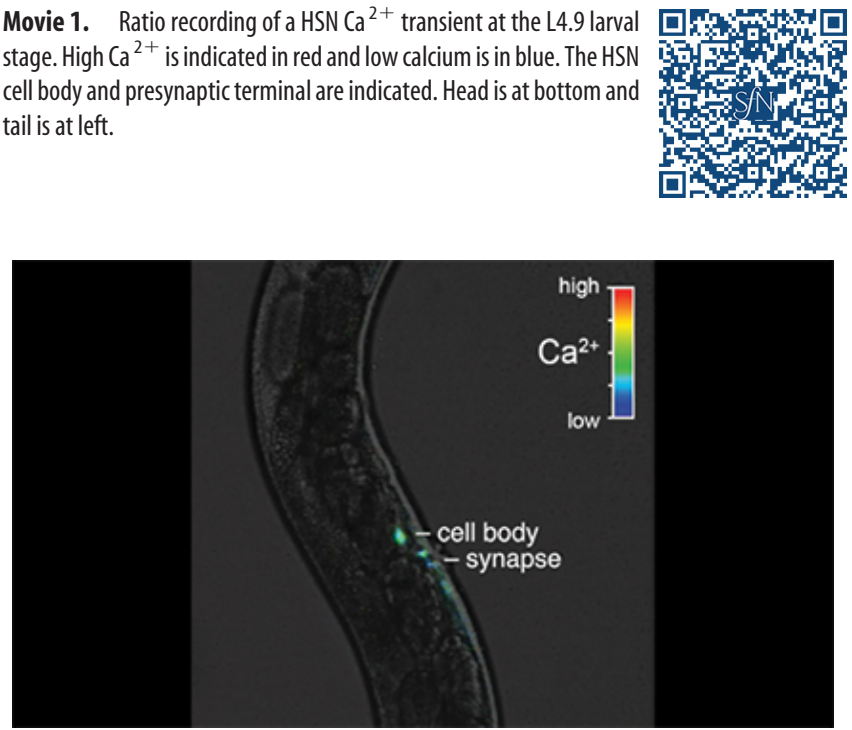

Movie 2. Ratio recording of a $\mathrm{HSN} \mathrm{Ca}^{2+}$ transient before an egglaying event in an adult animal during the active state. High $\mathrm{Ca}^{2+}$ is indicated in red and low calcium is in blue. The HSN cell body and presynaptic terminal are indicated. Head is at bottom and tail is at top.

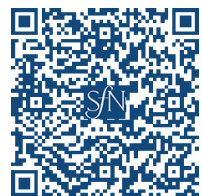

after $(15 \pm 7 \%)$, or before and after $(20 \pm 7 \%)$ the transient $(n=$ 156 transients). These results show that, although $\mathrm{HSN} \mathrm{Ca}{ }^{2+}$ transients can occur around locomotion events, there does not appear to be a causal relationship between HSN activity and movement in juvenile animals. We anticipate that these differences in HSN activity during locomotion are related to developmental changes in HSN serotonin levels. Adult HSNs show increased GFP expression from a tryptophan hydroxylase ( $t p h-1)$ transcriptional reporter (data not shown) and have elevated serotonin levels as measured by immunostaining (Desai et al., 1988).

\section{Vulval muscle $\mathrm{Ca}^{2+}$ transients increase in strength and} frequency during development

We next wanted to determine whether the HSN activity that we observed in late L4 animals drives early vulval muscle activity. We used the ceh-24 promoter to drive expression of GCaMP5 and mCherry in the vulval muscles of L4 animals. We detected $\mathrm{Ca}^{2+}$ transients at the L4.7-8 larval stage in the still-developing vulval muscles and these transients continued and increased in frequency as the muscles completed their development at the L4.9 stage (Fig. 3A-C, F, G, Movies 3, 4, and 5). The median interval between vulval muscle $\mathrm{Ca}^{2+}$ transients was $\sim 32 \mathrm{~s}$ in L4.7-8 an- 


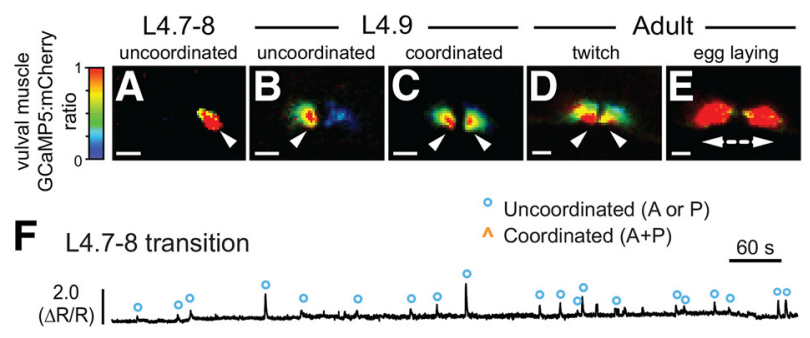

L4.9
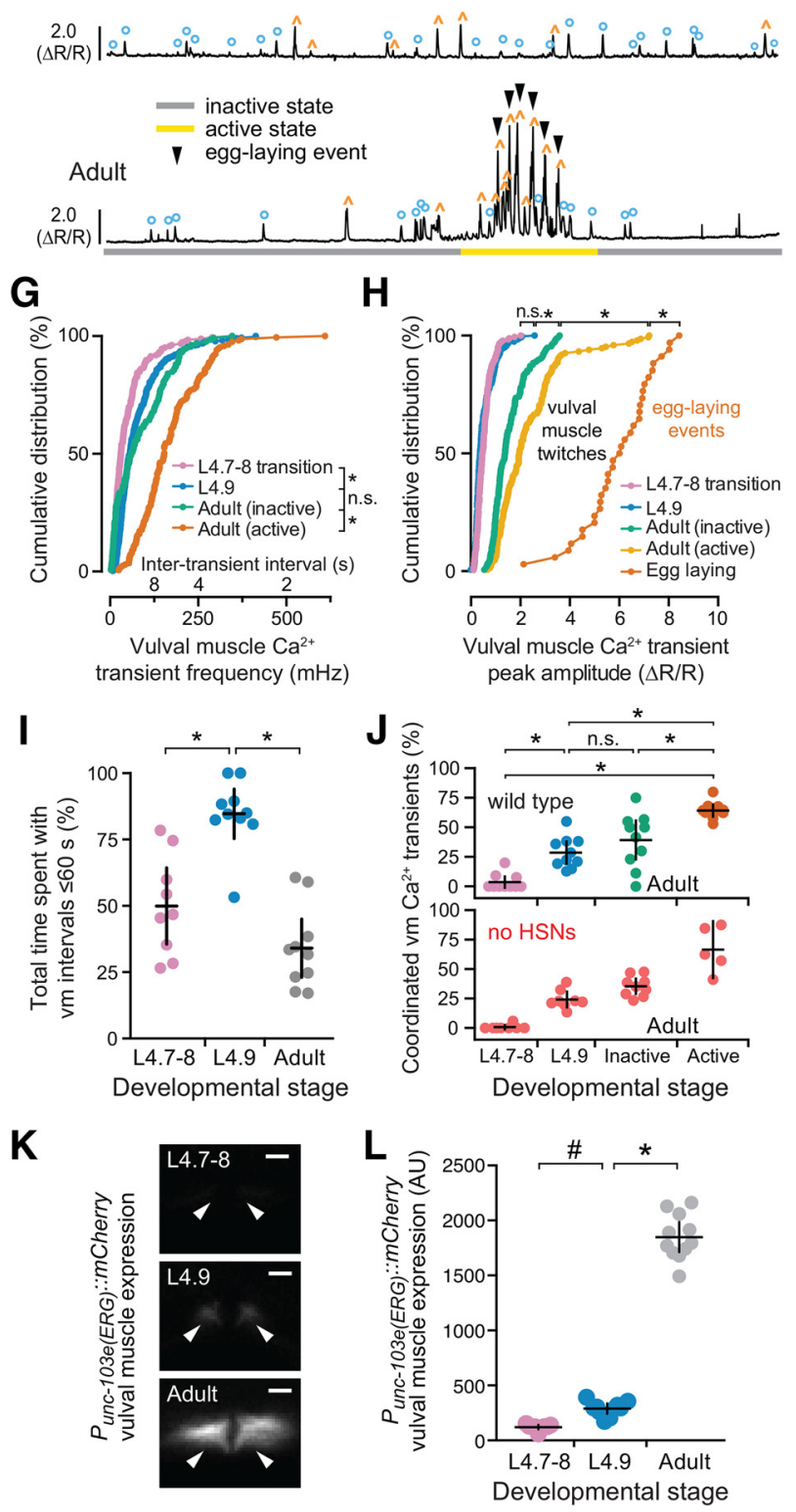

Figure 3. Development of coordinated vulval muscle $\mathrm{Ca}^{2+}$ transients in the L4.9 stage does not require presynaptic HSN input. $\boldsymbol{A}-\boldsymbol{E}$, Representative images of the intensity-modulated GCaMP5:mCherry fluorescence ratio during vulval muscle $\mathrm{Ca}^{2+}$ transients at the $\mathrm{L} 4.7-8(\boldsymbol{A})$, L4.9 larval stages $(\boldsymbol{B}, \boldsymbol{C})$, and during the adult active state $(\boldsymbol{D}, \boldsymbol{E})$. White arrowheads show localization of $\mathrm{Ca}^{2+}$ transients. Scale bars, $10 \mu \mathrm{m}$. Anterior is at left and ventral at bottom. See also Movies 3-6.F, Representative GCaMP5:mCherry $(\Delta R / R)$ ratio traces of vulval muscle $\mathrm{Ca}^{2+}$ activity at L4.7-8 (top), L4.9 (middle), and in adult animals (bottom) during an inactive (gray) and active (yellow) egg-laying state. Uncoordinated transients are indicated by blue circles, coordinated transients by orange carets, egg-laying events by black arrowheads. $\boldsymbol{G}, \boldsymbol{H}$, Cumulative distribution plots of instantaneous vulval muscle $\mathrm{Ca}^{2+}$ transient peak frequencies $(\boldsymbol{G})$ and amplitudes $(\boldsymbol{H})$ at L4.7-8 (pink), L4.9 (blue), and in the egg-laying inactive (green) and active state (orange) of adults. ${ }^{*} p<0.0001$; n.s. indicates $p>0.9999$

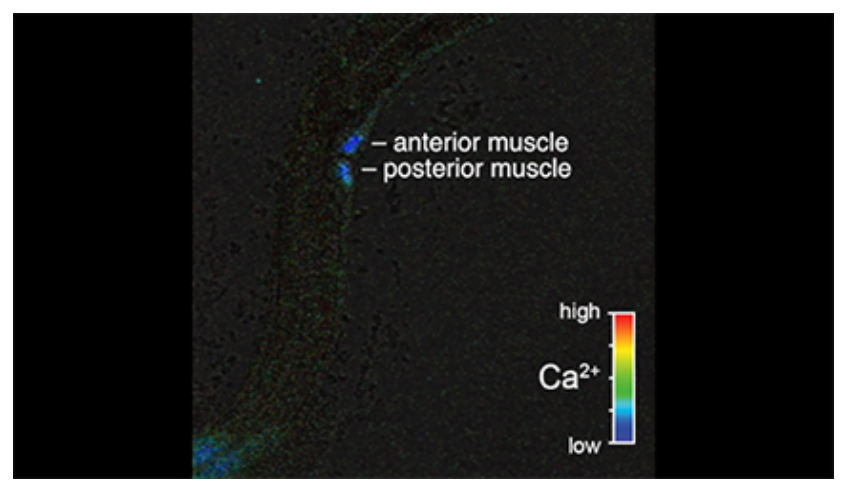

Movie 3. Ratio recording of an uncoordinated vulval muscle $\mathrm{Ca}^{2+}$ transient at the L4.7-8 larval stage. High $\mathrm{Ca}^{2+}$ is indicated in red and low calcium is in blue. Developing anterior and posterior vulval muscles are indicated. Head is at top and tail is at bottom.
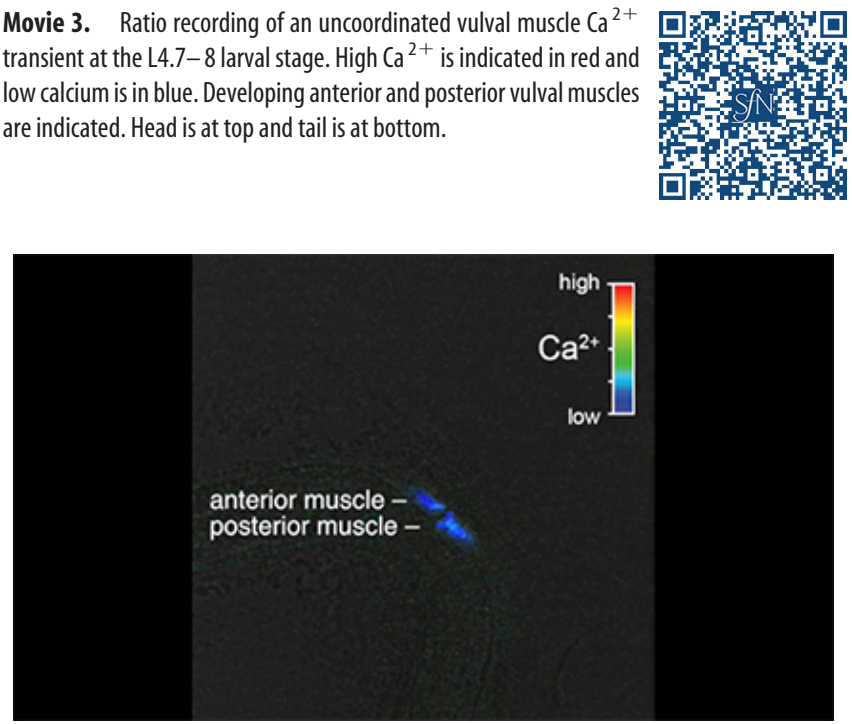

Movie 4. Ratio recording of an uncoordinated vulval muscle $\mathrm{Ca}^{2+}$ transient at the L4.9 larval stage. High $\mathrm{Ca}^{2+}$ is indicated in red and low calcium is in blue. Anterior and posterior vulval muscles are indicated. Head is at left and tail is at bottom.

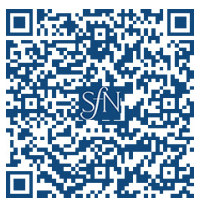

imals, which dropped to $18 \mathrm{~s}$ in L4.9 animals. L4 vulval muscle activity differs from that observed previously in egg-laying adults (Fig. $3 D, E$, Movie 6). The frequency of vulval muscle $\mathrm{Ca}^{2+}$ transients increased significantly in animals during the egg-laying active state, with median intervals dropping to $\sim 7 \mathrm{~s}$ phased with each body bend (Fig. $3 G$ ), as described previously (Collins and Koelle, 2013; Collins et al., 2016). We found that vulval muscle $\mathrm{Ca}^{2+}$ transients become stronger after development. Although $\mathrm{Ca}^{2+}$ transient amplitudes in the L4.7-8 and L4.9 stages were not

(Kruskal-Wallis test). $I$, Scatterplots show time spent by $9-10$ animals with frequent $\mathrm{Ca}^{2+}$ transients (intertransient intervals $\leq 60 \mathrm{~s}$ ) at L4.7-8 (pink), $L 4.9$ (blue), and in adults (gray). Error bars indicate $95 \%$ confidence interval for the mean. ${ }^{*} p \leq 0.0002$, one-way ANOVA. J Scatterplots showing percentage synchronous anterior and posterior vulval muscle $\mathrm{Ca}^{2+}$ transients in each individual at L4.7-8 (pink), L4.9 (blue), and in adult egg-laying inactive (green) and active states (orange) in wild-type (top) and egl-1(n986dm) animals (red) lacking HSNs (bottom). Error bars indicate $95 \%$ confidence intervals for the mean from $\geq 5$ animals. ${ }^{*} p \leq$ 0.0022 ; n.s. indicates $p \geq 0.1653$, one-way ANOVA. $\boldsymbol{K}$, Representative images of mCherry fluorescence in the vulval muscles from a unc-103e (ERG) transcriptional reporter in an L4.7-8, L4.9, and adult animal. White arrowheads show anterior (left) and posterior (right) vulval muscle cells. Scale bar, $10 \mu \mathrm{m}$. $L$, Scatterplots showing mCherry fluorescence from the unc103 e promoter in 10 animals. Error bars indicate $95 \%$ confidence interval for the mean. \#p= $0.0288 ;{ }^{*} p \leq 0.0001$, one-way ANOVA 


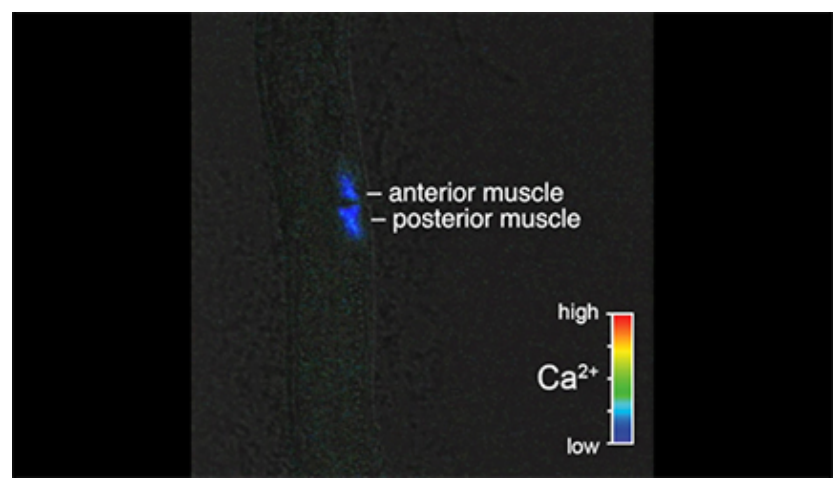

Movie 5. Ratio recording of a coordinated vulval muscle $\mathrm{Ca}^{2+}$ transient at the L4.9 larval stage. High $\mathrm{Ca}^{2+}$ is indicated in red and low calcium is in blue. Anterior and posterior vulval muscles are indicated. Head is at top and tail is at bottom.
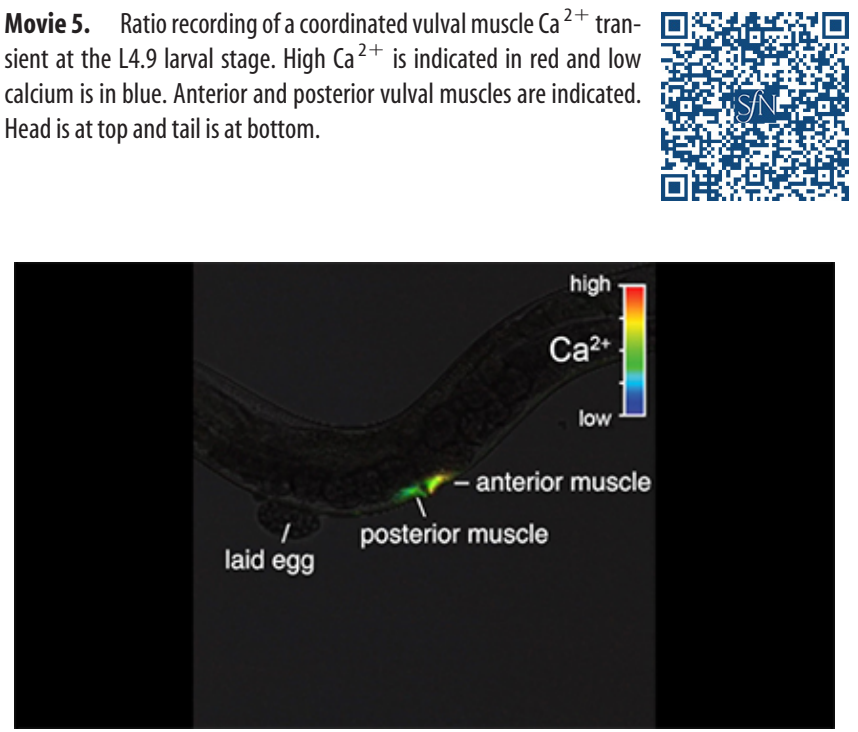

Movie 6. Ratio recording of coordinated vulval muscle $\mathrm{Ca}^{2+}$ transients during egg laying in adult animals. High $\mathrm{Ca}^{2+}$ is indicated in red and low calcium is in blue. The anterior and posterior vulval muscles are indicated, along with a previously laid egg. Head is at right and tail is at left.

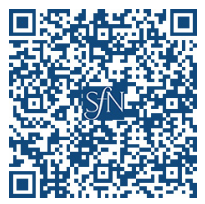

significantly different, inactive phase $\mathrm{Ca}^{2+}$ transients of adults were stronger than those observed in $\mathrm{L} 4$ animals (Fig. $3 \mathrm{H}$ ). In adult animals, strong $\mathrm{Ca}^{2+}$ transients were observed during the egg-laying active states, with the strongest $\mathrm{Ca}^{2+}$ transients driving the complete and simultaneous contraction of anterior and posterior vulval muscles to allow egg release (Fig. $3 E, H$ ).

We were surprised that vulval muscle transient frequencies decreased in adults as circuit activity bifurcated into distinct inactive and active egg-laying behavior states. We quantified periods of increased activity by measuring time spent with vulval muscle $\mathrm{Ca}^{2+}$ transient intervals $<1 \mathrm{~min}$. We found that vulval muscle activity increased as L4.7-8 animals developed into L4.9 animals, but then dropped significantly in egg-laying adults. L4.7-8 animals on average spent $\sim 50 \%$ of their time in periods of increased vulval muscle activity and this increased to $85 \%$ as animals entered the L4.9 stage (Fig. 3I). In contrast, adult animals spent only $\sim 33 \%$ of their time in periods with elevated vulval muscle activity (Fig. 3I) approximately half of which were coincident with the $\sim 3$ min egg-laying active states that occur approximately every $20 \mathrm{~min}$ (Waggoner et al., 1998). What depresses vulval muscle activity in adult animals? We have shown previously that the loss of unc-103, which encodes ERG K ${ }^{+}$channel, results in increased vulval muscle excitability and egg-laying behavior (Collins and Koelle, 2013). Using an mCherry transcriptional reporter transgene, we found that unc-103e expression in vulval muscles is low in L4 animals and increases $>15$-fold as animals mature into egg-laying adults (Fig. $3 K, L$ ). These results are consistent with our previous functional results showing that that ERG depresses vulval muscle electrical excitability in adults to promote distinct inactive and active egg-laying behavior states (Collins and Koelle, 2013).

\section{Development of coordinated vulval muscle activity for egg laying}

Egg release through the vulva requires the synchronous contraction of the anterior and posterior vulval muscles (Fig. 3E). Previous work has shown that loss of Notch signaling blocks postsynaptic vm 2 muscle arm development in L4 animals, resulting in asynchronous vulval muscle contractility and defects in egg release in adults (Li et al., 2013). Because of the vulval slit, the lateral vm2 muscle arms that develop between L4.7-8 and L4.9 form the only sites of potential contact between the anterior and posterior vulval muscles (Fig. $1 M, N$ ). To determine the relationship between vulval muscle morphology and activity, we examined the spatial distribution of vulval muscle $\mathrm{Ca}^{2+}$ during identified transients. We found that only $5 \%$ of vulval muscle $\mathrm{Ca}^{2+}$ transients were coordinated in the L4.7-8 stage (Fig. 3A, Movie 3), with nearly all transients occurring in either the anterior or posterior muscles (Fig. $3 F, J$ ). The degree of vulval muscle coordination increased significantly to $\sim 28 \%$ of transients during L4.9 (Fig. 3J; cf. Movies 4 and 5), a time when vm1 and vm2 muscles, as well as vm 2 muscle arms, complete their development (cf. Fig. $1 M, N$ ). This level of coordinated muscle activity was not significantly different from that found in adult animals during the egg-laying inactive state (Fig. 3J; cf. Fig. 3C,D). During the egg-laying active state, $\sim 60 \%$ of vulval muscle transients were found to be coordinated, with $\mathrm{Ca}^{2+}$ transients occurring synchronously in the anterior and posterior muscles (Movie 6).

To test whether HSN activity was required for the development of coordinated muscle activity, we analyzed muscle activity in animals missing the HSNs. Surprisingly, we observed that vulval muscles develop wild-type levels of coordinated activity even without HSN input (Fig. 3J). We have shown previously that vulval muscle activity in adults is phased with locomotion (Collins et al., 2016), possibly via rhythmic acetylcholine release from the VA7 and VB6 motor neurons that synapse onto the vm1 muscles (White et al., 1986). Vulval muscle activity in L4.9 animals accompanied ongoing locomotion as well. We analyzed recordings from L4.9 animals for movement 10 seconds before and after each vulval muscle $\mathrm{Ca}^{2+}$ transient. A clear majority of transients $(62 \pm 5 \%)$ were accompanied by movements occurring both before and after vulval muscle activity, with a smaller fraction of transients occurring just before or just after movement ( $11 \pm 4 \%$ and $10 \pm 4 \%$, respectively; $n=291$ transients). Movement was not strictly required for vulval muscle activity because $\mathrm{Ca}^{2+}$ transients were still observed in nonmoving animals (17 $\pm 4 \%)$. Our results show that coordinated vulval muscle activity in L4.9 stage is independent of HSN input and may instead be driven by input from the locomotion motor neurons into vm 1 and through the lateral vm2 muscle contact along the vulval slit.

\section{Early neuronal and vulval muscle activity is not required for} the onset of adult egg-laying behavior

Activity in developing circuits has been shown previously to contribute to mature patterns of activity that drive behavior. Is the 

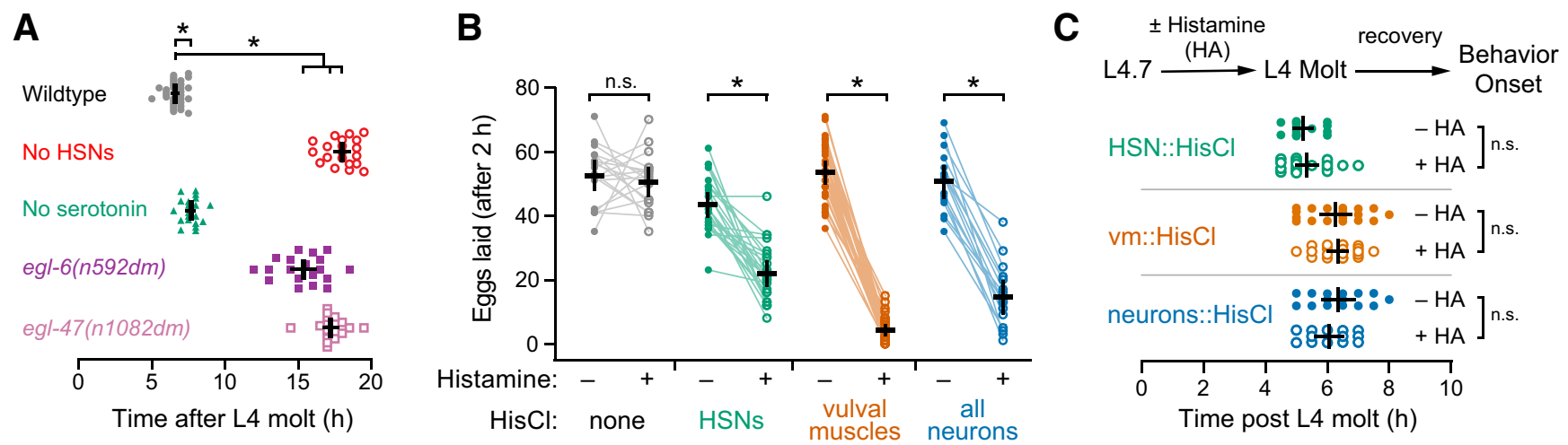

Figure 4. Early HSN and vulval muscle activity is not required for the onset of egg-laying behavior. A, Scatter plots of the first egg-laying event in wild-type (gray), HSN-deficient egl-1 (n986dm) (red open circles), serotonin-deficient tph-1(mg280) (green triangles), egl-6(n592dm) (purple squares), and egl-47(n1082dm) (pink open squares) mutant animals. Error bars indicate $95 \%$ confidence intervals for the mean from $\geq 19$ animals. ${ }^{*} p \leq 0.0016$, one-way ANOVA. $B$, Scatter plots showing eggs laid by $324 \mathrm{~h}$ adult animals in $2 \mathrm{~h}$ before (filled circles) and in $2 \mathrm{~h}$ after incubation on plates with $10 \mathrm{~mm}$ histamine (open circles). Transgenic animals expressing His(l in vulval muscles (orange), HSN neurons (green), all neurons (blue) were compared with the nontransgenic wild-type (gray). Error bars indicate $95 \%$ confidence intervals for the mean from $\geq 17$ paired replicates. ${ }^{*} p<0.0001$; $n$.s. indicate $p=0.5224$, paired Student's t test. C, Top, Transgenic L4.7 animals expressing HisCl channels were incubated on NGM plates with or without $10 \mathrm{~mm}$ histamine until the L4 adult molt. Animals were then moved to plates lacking histamine and allowed to recover and lay eggs. Bottom, Scatter plots showing the timing of the first egg-laying event with (open circles) and without (filled circles) histamine. Error bars indicate $95 \%$ confidence intervals for the mean; n.s. indicates $p>0.9999$, one-way ANOVA.

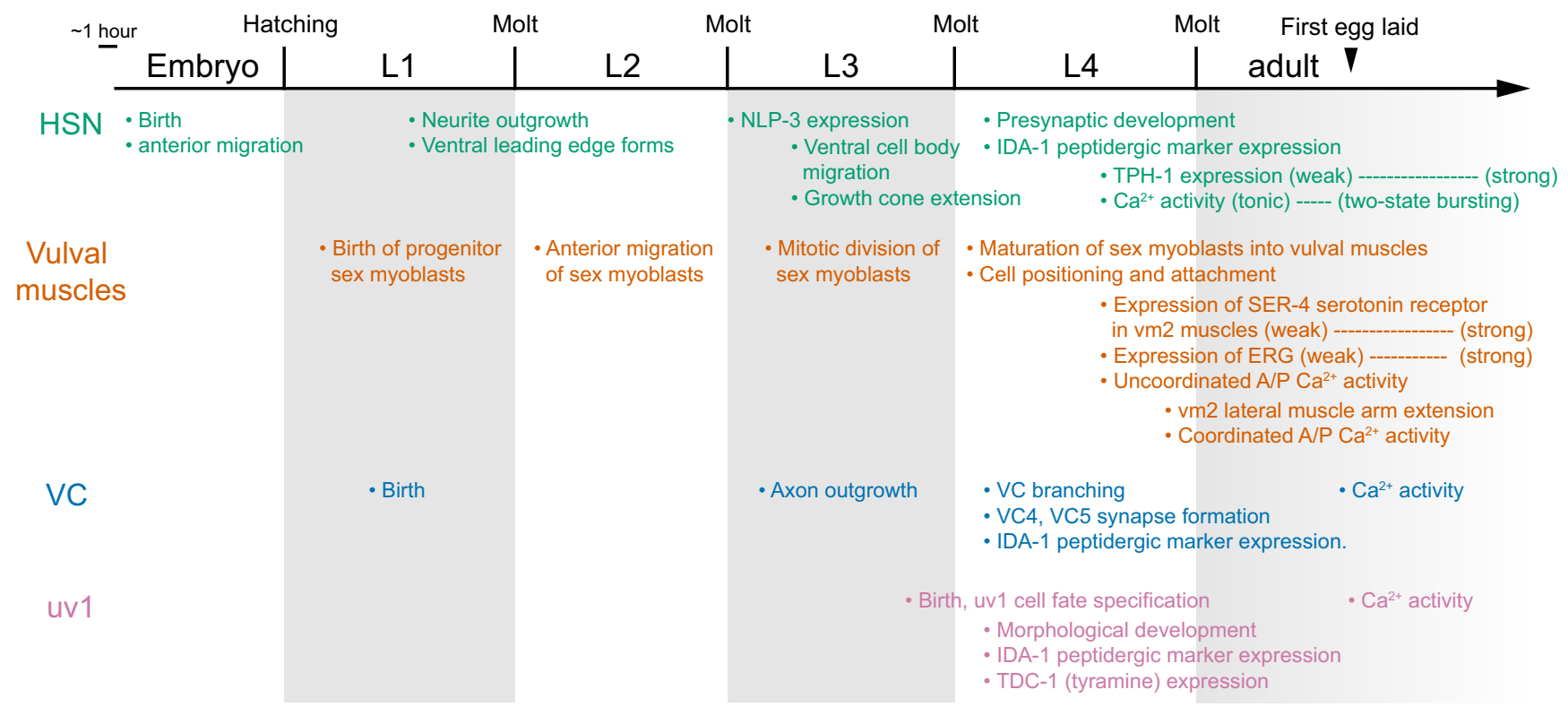

Figure 5. Timeline of key developmental events and the onset of $\mathrm{Ca}^{2+}$ activity in the C. elegans egg-laying circuit. The HSNs complete their morphological and synaptic development by the early to mid-L4 stages, synthesize TPH-1 for serotonin biosynthesis (weakly during late L4) and NLP-3 (expression levels comparable to adults) during L4, and show $\mathrm{Ca}^{2+}$ activity beginning at late L4 (Shen and Bargmann, 2003; Shen et al., 2004; Adler et al., 2006; Patel et al., 2006). The vulval muscles complete their morphological development toward the end of the late L4 (Sulston and Horvitz, 1977; Burdine et al., 1997, 1998; Li et al., 2013), weakly express the SER-4 serotonin receptor in vm2 during L4, and show Ca ${ }^{2+}$ activity beginning at approximately mid-L4 (concomitant with morphological development). ERG K ${ }^{+}$channel expression in muscles increases from $\mathrm{L} 4$ to adults as spontaneous muscle $\mathrm{Ca}^{2+}$ transients decrease in frequency. The VC neurons and uv1 cells complete their morphological development before the late L 4 stage (Li and Chalfie, 1990; Newman et al., 1996). At this time, both VC and uv1 express the peptidergic marker IDA-1 and uv1 expresses TDC-1 for tyramine biosynthesis. VC and uv1 only show $\mathrm{Ca}^{2+}$ activity at the onset of egg-laying behavior in young adults.

early activity that we observed in HSN and vulval muscles required for the proper onset of egg-laying behavior in adults? To test this, we first set out to determine when adults initiate egg laying. We found that wild-type animals laid their first egg at $\sim 6-7 \mathrm{~h}$ after the L4 adult molt (Fig. $4 A$ ) after accumulating $\sim 8-10$ eggs in the uterus, a time when $\mathrm{VC}$ and uv1 $\mathrm{Ca}^{2+}$ activity is first observed (data not shown). Animals without HSNs laid their first egg much later, $\sim 18 \mathrm{~h}$ after molt (Fig. $4 A$ ). Gain-offunction receptor mutations in EGL-6, a neuropeptide receptor coupled to $\mathrm{G} \alpha_{\mathrm{o}}$ (Ringstad and Horvitz, 2008), or EGL-47, a putative gustatory receptor, block neurotransmitter release from
HSN (Moresco and Koelle, 2004) and delay egg release until $\sim 15-17 \mathrm{~h}$ after the L4 molt, resembling animals without HSNs (Fig. 4A). Surprisingly, tph-1 knock-out animals that are unable to synthesize serotonin showed only a small, albeit significant, delay in egg release compared with wild-type $(\sim 7-8 \mathrm{~h}$ after L4 molt), suggesting that HSN promotes egg laying via release of neurotransmitters other than serotonin.

To silence HSN and vulval muscle activity acutely and reversibly, we expressed Drosophila Histamine-gated chloride channel ( $\mathrm{HisCl})$ using cell-specific promoters and tested how histamine affected egg-laying behavior (Pokala et al., 2014). Egg laying was 


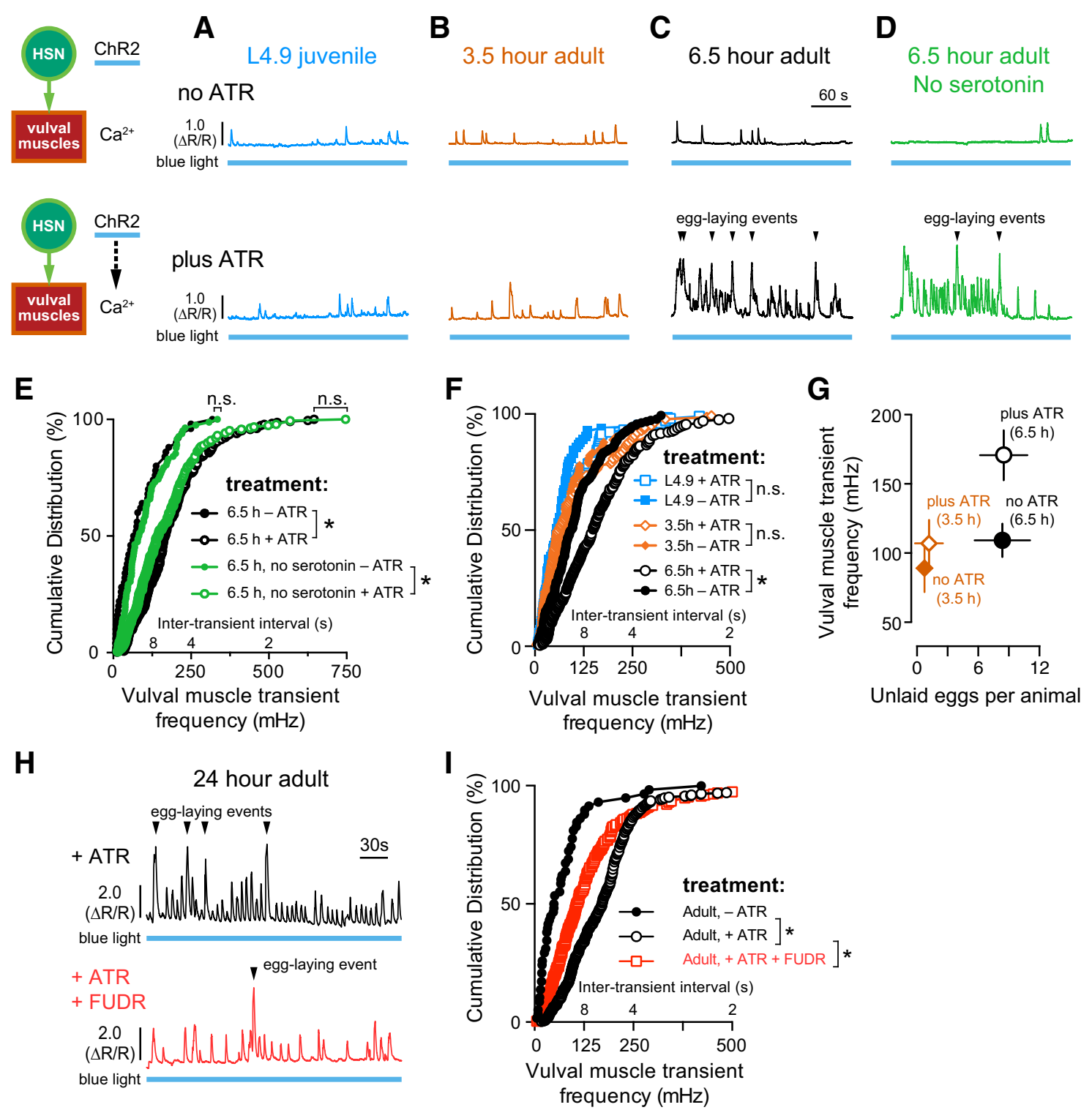

Figure 6. Vulval muscle responsiveness to HSN input correlates with egg accumulation. $\boldsymbol{A}-\boldsymbol{D}$, Representative traces of vulval muscle $\mathrm{Ca}^{2+}$ activity in $\mathrm{L} 4.9$ juveniles $(\boldsymbol{A}$, blue), $3.5 \mathrm{~h}$ adults ( $\boldsymbol{B}$, orange), $6.5 \mathrm{~h}$ wild-type adults ( $\boldsymbol{C}$, black), and $6.5 \mathrm{~h}$ serotonin-deficient $t p h-1(\mathrm{mg} 280)$ mutant adults $(\boldsymbol{D}$, green) with and without optogenetic activation of HSN. Animals were grown in the presence ( + ATR, top) or absence (-ATR, bottom) of ATR (see diagram). Continuous $489 \mathrm{~nm}$ laser light was used to stimulate HSN ChR2 activity and excite GCaMP5 fluorescence simultaneously for the entire recording. Arrowheads indicate egg-laying events. Blue bars under the $\mathrm{Ca}^{2+}$ traces indicate the period of continuous blue light exposure. $\boldsymbol{E}$, Cumulative distribution plots of instantaneous peak frequencies (and intertransient intervals) of vulval muscle $\mathrm{Ca}^{2+}$ activity in $6.5 \mathrm{~h}$ adult wild-type (black filled circles, no ATR; black open circles, plus ATR) and tph-1(mg280) mutant animals (green filled circles, no ATR; green open circles, plus ATR). ${ }^{*} p<0.0001$; n.s. indicates $p \geq 0.2863$, Kruskal-Wallis test. $\boldsymbol{F}$, Cumulative distribution plots of instantaneous peak frequencies (and intertransient intervals) of vulval muscle $\mathrm{Ca}^{2+}$ activity in L4.9 juveniles (blue filled squares, no ATR; blue open squares, plus ATR), $3.5 \mathrm{~h}$ adults (orange filled circles, no ATR; orange open circles, plus ATR), and $6.5 \mathrm{~h}$ adults (black filled circles, no ATR; black open circles, plus ATR). ${ }^{*} p<0.0001$; n.s. indicates $p \geq 0.3836$, Kruskal-Wallis test. $G$, Plot showing the average number of unlaid eggs present in the uterus and the average vulval muscle $\mathrm{Ca}^{2+}$ transient peak frequency, $\pm 95 \%$ confidence intervals. $\boldsymbol{H}$, Representative traces of $\mathrm{HSN}$-induced vulval muscle $\mathrm{Ca}^{2+}$ activity in untreated (top, black) and FUDR-treated $24 \mathrm{~h}$ adult animals (bottom, red). Arrowheads indicate egg-laying events. I, Cumulative distribution plots of instantaneous peak frequencies (and intertransient intervals) of vulval muscle $\mathrm{Ca}^{2+}$ activity after optogenetic activation of HSNs in untreated animals grown with ATR (+ ATR, open black circles), FUDR-treated animals with ATR ( + ATR, open red circles), and in untreated animals without ATR (no ATR, filled black circles). ${ }^{*} p<0.0001$, Kruskal-Wallis test.

unaffected by exogenous histamine in nontransgenic animals, but was potently inhibited when $\mathrm{HisCl}$ channels were expressed transgenically in the HSNs, the vulval muscles, or in the entire nervous system (Fig. 4B). Silencing these cells in late L4 animals for the entire period when we observed early activity caused no significant changes in the onset of adult egg laying after histamine washout in molted adults (Fig. 4C). We also observed no change in the steady-state number of unlaid eggs in the uterus after developmental silencing of L4 animals with histamine (data not shown). These results suggest that presynaptic and postsynaptic activity in the developing circuit is not required for circuit development or behavior.

Figure 5 summarizes the timeline of key developmental events in the egg-laying circuit (HSN, VC, vulval muscles, and uvl cells) from birth of the individual cells/precursors to their final differentiated state in adults: (1) morphological and synaptic development, (2) neurotransmitter/neuropeptide/receptor specification, and (3) the onset of early and mature patterns of $\mathrm{Ca}^{2+}$ activity. Similar to morphological development, which occurred asynchronously in the egg-laying circuit (Fig. 1), we observed that the 
A
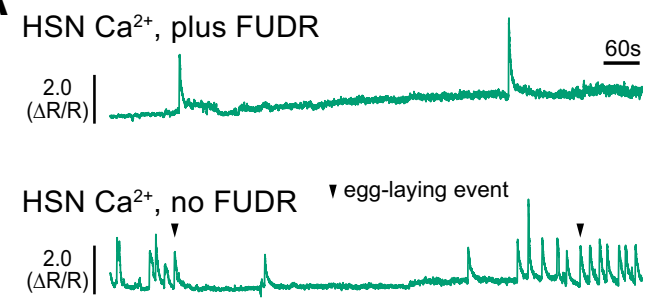

B

HSN Ca ${ }^{2+}, g l p-1$ (or178ts)
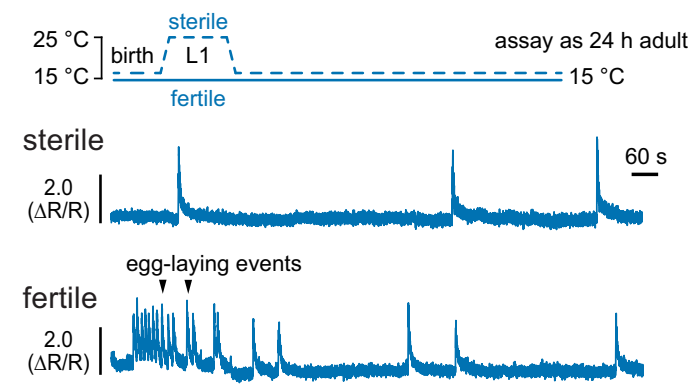

C

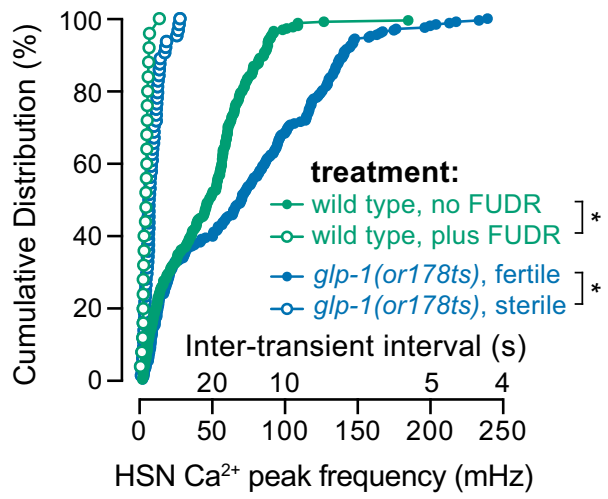

D

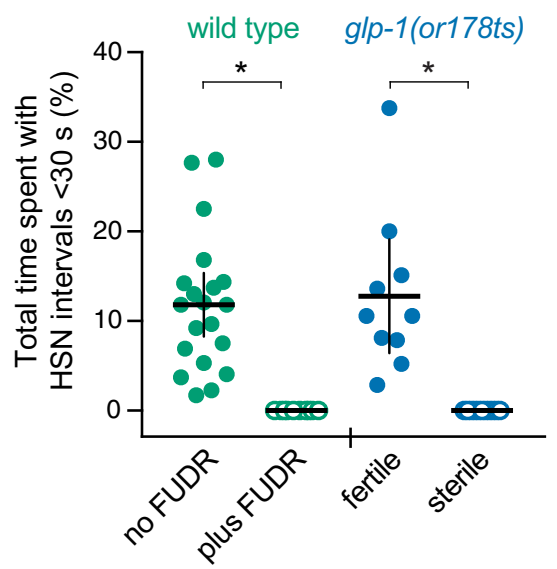

Figure 7. Germline activity is required for HSN burst firing and the active state. $A$, Representative HSN Ca ${ }^{2+}$ traces in untreated (top) and FUDR-treated (bottom) adult animals. $\boldsymbol{B}$, Representative HSN Ca ${ }^{2}$ traces in adult glp-1(or178ts) sterilized animals (L1s shifted to $25^{\circ} \mathrm{C}$ for $24 \mathrm{~h}$ and raised to adults at $15^{\circ} \mathrm{C}$ ) (top) and $g / p-1$ (or $\left.178 t s\right)$ fertile animals (raised at $15^{\circ} \mathrm{C}$ ) (bottom). Arrowheads indicate egg laying events. C, Cumulative distribution plots of instantaneous HSN $\mathrm{Ca}^{2+}$ transient peak frequencies (and intertransient intervals) of adult $\mathrm{HSN} \mathrm{Ca}^{2+}$ activity. ${ }^{*} p<0.0001$, Kruskal-Wallis test. $\boldsymbol{D}$, Scatterplots showing total time spent by each individual with HSN transients $\leq 30 \mathrm{~s}$ apart in untreated (green filled circles) and FUDR-treated (green open circles) wild-type animals or fertile (blue filled circles) or sterile (blue open circles) $g / p$ 1 (or178ts) mutant animals. ${ }^{*} p \leq 0.0001$, one-way ANOVA. Error bars indicate $95 \%$ confidence intervals for the mean. onset of activity in the cells of the circuit occurred at different developmental stages and continued to be shaped after morphological development (in the case of HSN and vulval muscles). Patterns of activity characteristic of adult egg-laying behavior were observed for all cells by the time the first egg was laid in $\sim 6-7$ hour old adults.

\section{Vulval muscle responsiveness to HSN activity increases as} maturing animals accumulate unlaid eggs

We and others have shown previously that optogenetic activation of the HSNs in adult animals is sufficient to induce egg-laying circuit activity and behavior (Emtage et al., 2012; Collins et al., 2016). Despite the fact that both the HSNs and vulval muscles show activity in L4.9 animals, egg laying does not begin until 6-7 $\mathrm{h}$ later, when the animals have accumulated $\sim 8-10$ unlaid eggs in the uterus. To determine the relationship between developmental time, egg production, and circuit functionality, we tested when the vulval muscles develop sensitivity to HSN input. We activated the HSNs optogenetically using ChR2 while simultaneously recording $\mathrm{Ca}^{2+}$ activity in the vulval muscles at 3 stages: in L4.9 juveniles and in 3.5-h- and 6.5-h-old adults. L4.9 animals have no eggs in the uterus, $3.5 \mathrm{~h}$ adults contained $0-1$ unlaid eggs, and $6.5 \mathrm{~h}$ adults had accumulated $\sim 8-10$ eggs. Stimulating HSNs in L4.9 juveniles or in $3.5 \mathrm{~h}$ adults failed to induce detectable changes in vulval muscle $\mathrm{Ca}^{2+}$ activity (Fig. $6 A, B, F$ ). In contrast, optogenetic activation of HSNs in $6.5 \mathrm{~h}$ adults increased vulval muscle $\mathrm{Ca}^{2+}$ activity significantly and triggered egg laying (Fig. $6 C, F)$. L4.9 juveniles or $3.5 \mathrm{~h}$ adults with $0-1$ eggs in the uterus had a mean transient frequency of $\leq 100 \mathrm{mHz}$, similar to the inactive state vulval muscle $\mathrm{Ca}^{2+}$ response seen in $6.5 \mathrm{~h}$ adult animals with $\sim 8$ unlaid eggs grown in the absence of ATR, a cofactor necessary for ChR2 activation. The vulval muscle $\mathrm{Ca}^{2+}$ response to HSN input was increased to $\sim 170 \mathrm{mHz}$ in $6.5 \mathrm{~h}$ adults that had accumulated $\sim 8$ unlaid eggs (Fig. $6 G$ ). Surprisingly, vulval muscles in serotonin-deficient mutants responded normally to HSN activation at $6.5 \mathrm{~h}$ (Fig. $6 D, E$ ), a finding consistent with the normal onset of egg laying in these mutants (Fig. $4 A)$. Together, these results show that, despite having significant $\mathrm{Ca}^{2+}$ activity in juveniles, the adult vulval muscles only develop a robust response to HSN input $\sim 6 \mathrm{~h}$ after the molt, a time when fertilized embryos are being deposited in the uterus to be laid.

We next investigated whether this change in vulval response in older adults was caused by ongoing developmental events or was instead a consequence of egg accumulation. We demonstrated previously that adults sterilized with FUDR, a chemical blocker of germline cell division and egg production, showed inactive state levels of vulval muscle activity (Collins et al., 2016). We found that vulval muscles in FUDR-treated animals $24 \mathrm{~h}$ after the molt were also significantly less responsive to HSN optogenetic stimulation (Fig. $6 \mathrm{H}, I$ ). The residual vulval muscle response in FUDR-treated animals is likely caused by incomplete sterilization when FUDR is added to L4.9 animals. We interpret these results as indicating that animal age or circuit maturity is not sufficient for the onset of the egg-laying active state.

\section{Retrograde signal of egg accumulation and vulval muscle} activity drives presynaptic HSN activity

HSN activity can be inhibited by external sensory signals and feedback of egg release (Ringstad and Horvitz, 2008; Emtage et al., 2012; Collins et al., 2016; Banerjee et al., 2017), but the factors that promote HSN activity are not clear. We tested whether egg accumulation promotes circuit activity through the presynaptic HSNs, the postsynaptic vulval muscles, or both. We found that 
A vulval muscle (vm)::HisCl

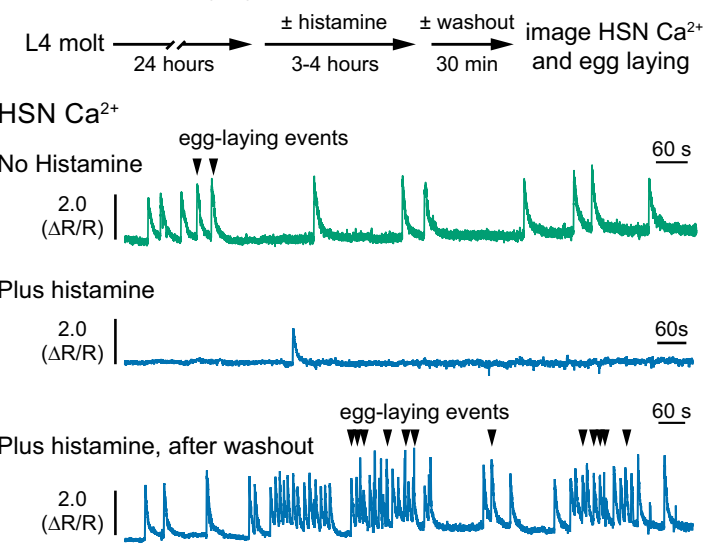

B

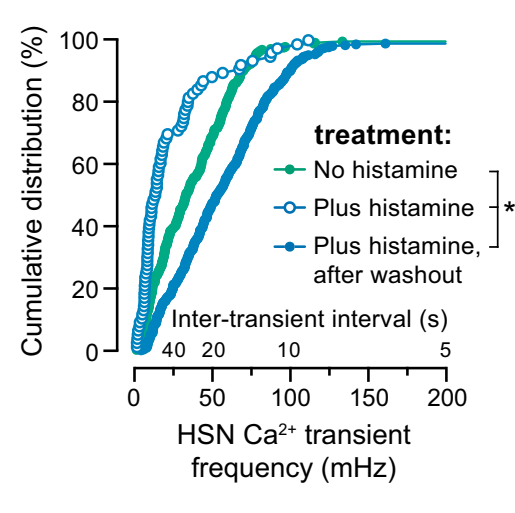

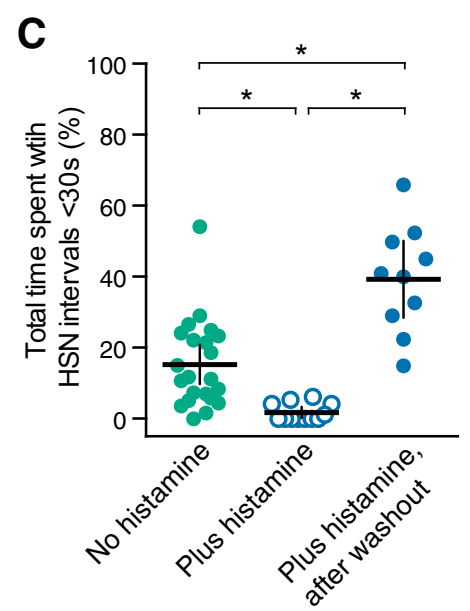

Figure 8. Vulval muscle activity and egg accumulation promote HSN burst firing. $\boldsymbol{A}$, Adult animals (24h) expressing HisCl in the postsynaptic vulval muscles (vm) and GCaMP5/mCherry in the presynaptic HSNs were placed onto NGM plates with (blue, bottom) or without histamine (green, top) for $3-4 \mathrm{~h}$ to induce muscle silencing and cessation of egg laying. Animals were then moved to plates without histamine and allowed to recover for $30 \mathrm{~min}$ before $\mathrm{HSN} \mathrm{Ca}^{2+}$ imaging. $\mathrm{HSN} \mathrm{Ca}^{2+}$ imaging was also performed on adults not removed from histamine (blue, middle). Arrowheads indicate egg-laying events. B, Cumulative distribution plots of instantaneous HSN Ca ${ }^{2+}$ transient peak frequencies (and intertransient intervals) on histamine (open blue circles), and after histamine washout (filled blue circles) compared with untreated controls (filled green circles). ${ }^{*} p<0.0001$, Kruskal-Wallis test. C, Scatter plots show fraction of time spent by each individual with frequent HSN Ca ${ }^{2+}$ transients characteristic of the egg-laying active state $(<30 \mathrm{~s}$ ) in untreated controls (green circles), on histamine (blue open circles), and after histamine washout (blue circles). Error bars indicate $95 \%$ confidence intervals for the mean. ${ }^{*} p \leq 0.0061$, one-way ANOVA.

HSN $\mathrm{Ca}^{2+}$ activity, particularly the burst-firing activity associated with the active state, was dramatically reduced in FUDRtreated animals (Fig. 7A). Although we did observe single HSN $\mathrm{Ca}^{2+}$ transients after FUDR treatment, the intervals in between were prolonged, often minutes apart (Fig. 7C). We quantified the total time spent by animals with $\mathrm{HSN} \mathrm{Ca}{ }^{2+}$ transient intervals $<30 \mathrm{~s}$ apart as a measure of HSN burst-firing seen in the active state. We found that, although untreated animals spent $\sim 13 \%$ of their time with the HSNs showing high-frequency activity, such bursts were eliminated in FUDR-treated animals (Fig. 7D). We confirmed the FUDR results using a conditional $g l p-1$ (or178ts) Notch receptor mutant that causes germline loss and sterility when shifted to $25^{\circ} \mathrm{C}$ during the L1 stage (Fig. $7 B$ ). We observed a dramatic reduction in $\mathrm{HSN} \mathrm{Ca}{ }^{2+}$ transient frequency in sterile glp-1(or178ts) adults, phenocopying the results seen with FUDR (Fig. $7 \mathrm{~B}, C$ ). Whereas $g l p-1$ (or178ts) fertile animals (raised at $15^{\circ} \mathrm{C}$ ) animals spent a typical $13 \%$ of their time with the HSNs showing high-frequency activity, such bursts were eliminated in sterile $g l p-1$ (or178ts) adults (Fig. $7 D$ ). These results show that feedback of germline activity, egg production, and/or egg accumulation modulates the frequency of HSN activity.

We performed a reciprocal experiment to test how the accumulation of unlaid eggs would affect presynaptic HSN activity. We have shown previously that passage of eggs through the vulva mechanically activates the uv1 neuroendocrine cells that release tyramine and neuropeptides that inhibit HSN activity and egg laying (Collins et al., 2016; Banerjee et al., 2017). We hypothesized that prevention of egg release would block inhibitory uv1 feedback and increase HSN activity. We expressed HisCl channels in the vulval muscles and recorded $\mathrm{HSN} \mathrm{Ca}{ }^{2+}$ activity after silencing with exogenous histamine. Surprisingly, we found that acute silencing of vulval muscles reduced presynaptic $\mathrm{HSN} \mathrm{Ca}^{2+}$ activity significantly, resembling the effects of animal sterilization (Fig. $8 A, B$ ). Although untreated animals spent $\sim 16 \%$ of recording time with high-frequency HSN activity, this was reduced to $\sim 2 \%$ of the total recording time in histamine-treated animals (Fig. 8C). These results indicate that postsynaptic vulval muscle activity is required for the burst firing in the presynaptic HSN neurons that accompanies the egg-laying active state.
We next looked at how $\mathrm{HSN} \mathrm{Ca}^{2+}$ activity recovers when histamine inhibition of the vulval muscles and egg laying is reversed. As shown in Figure $8 A$, adult animals were treated with or without histamine for 3-4 h and then moved to plates without histamine for a 20-30 min recovery period. Presynaptic HSN $\mathrm{Ca}^{2+}$ activity was then recorded as the animals resumed egglaying behavior. The HSNs showed a rapid and dramatic recovery of $\mathrm{Ca}^{2+}$ activity after histamine washout resulting in a prolonged active state with increased $\mathrm{HSN} \mathrm{Ca}{ }^{2+}$ transient frequency and numerous egg-laying events (Fig. $8 A, B$ ). Washout animals spent $\sim 40 \%$ of their recorded time with elevated HSN activity compared with $15 \%$ of the total recorded time in untreated controls (Fig. 8C). During this recovery period, we observed increased vulval muscle twitching contractions in the bright-field channel, indicating that muscle activity was restored (data not shown). These results are consistent with a model whereby accumulation of unlaid eggs promotes vulval muscle activity, which drives a homeostatic increase in presynaptic HSN activity and burst firing that sustains egg laying.

HSN synapses are formed exclusively on the lateral vm2 muscle arms, which provide sites of contact between the anterior and posterior vulval muscles (White et al., 1986; Feinberg et al., 2008; Collins and Koelle, 2013). Hypomorphic Notch signaling mutants fail to develop vm2 muscle arms and are egg-laying defective, but have normal presynaptic HSN and VC development (Sundaram and Greenwald, 1993; Li et al., 2013). To determine whether retrograde signaling from the vulval muscles to the HSNs occurs through the vm2 muscle arms, we recorded HSN $\mathrm{Ca}^{2+}$ activity in lin-12(wy750) Notch receptor mutant animals (Fig. 9A,B). We found that $\mathrm{HSN} \mathrm{Ca}^{2+}$ transient frequency was strongly reduced in the lin-12(wy750) mutants compared with wild-type control animals (Fig. $9 C, D)$ ). $\mathrm{HSN} \mathrm{Ca}^{2+}$ transients still occurred in lin-12(wy750) mutants, but burst firing was eliminated. Wild-type animals spent $\sim 13 \%$ of their time with HSN transients $<30 \mathrm{~s}$ apart, whereas this was reduced to zero in the lin-12(wy750) mutant (Fig. 9E), resembling activity seen in sterilized or vulval muscle-silenced animals. Together, these results suggest that muscle activity feeds back through the vm 2 muscle arms onto the presynaptic HSN neurons to promote additional 
A

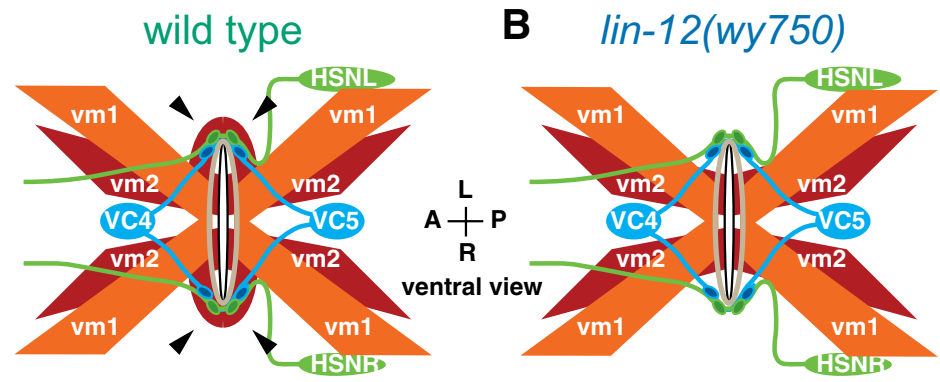

C $\mathrm{HSN} \mathrm{Ca}^{2+}$

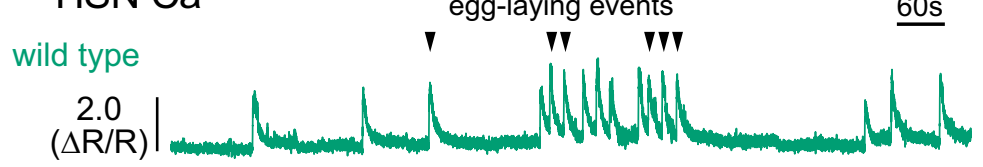

lin-12(wy750) egg-laying event

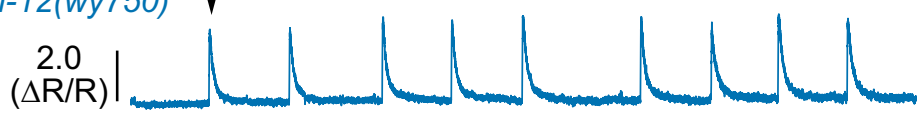

D
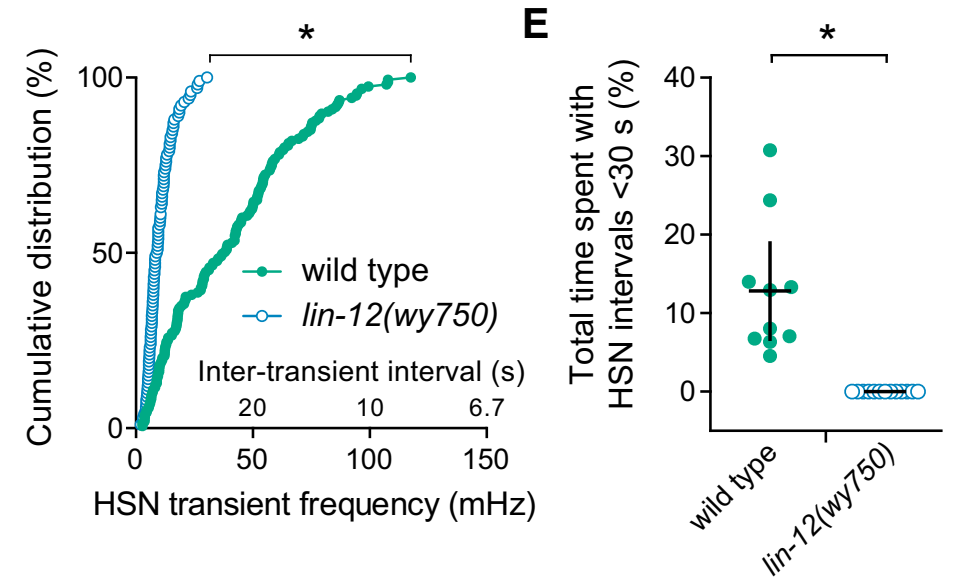

Figure 9. The vm2 muscle arms are required for vulval muscle feedback to HSN and burst firing. $A, B$, Diagram of egg-laying circuit structure (ventral view) in wild-type $(\boldsymbol{A})$ and lin-12(wy750) mutant $(\boldsymbol{B})$ animals missing lateral vm2 muscle arms (arrowheads). $\boldsymbol{C}$, Representative traces showing HSN $\mathrm{Ca}^{2+}$ activity in wild-type (green) and lin-12(wy750) mutant animals (blue). Arrowheads indicate egg-laying events. D, Cumulative distribution plots of instantaneous $\mathrm{Ca}^{2+}$ transient peak frequencies (and intertransient intervals) in wild-type (green circles) and lin-12 (wy750) mutants (blue circles). ${ }^{*} p<0.0001$, Mann-Whitney test. $\boldsymbol{E}$, Scatter plots showing fraction of time spent by each individual with frequent $\mathrm{HSN} \mathrm{Ca}^{2+}$ transients characteristic of the egglaying active state ( $<30$ s) in wild-type (filled green circles) and lin-12(wy750) mutant animals (open blue circles). Error bars indicate $95 \%$ confidence intervals for the mean. ${ }^{*} p=0.0011$, Student's $t$ test.

$\mathrm{Ca}^{2+}$ transients that drive burst firing and sustain the egg-laying active state.

\section{Discussion}

We used a combination of molecular genetic, optogenetic and chemogenetic, and ratiometric $\mathrm{Ca}^{2+}$ imaging approaches to determine how coordinated activity develops in the C. elegans egglaying behavior circuit. We found that the presynaptic HSNs, VCs, and uv1 neuroendocrine cells complete morphological development during early to mid-L4 stages, whereas the vulval muscles finish developing at the late L4 stages. Like HSNs, the vulval muscles show $\mathrm{Ca}^{2+}$ activity in the L4.7-8 stage. Coordinated vulval muscle $\mathrm{Ca}^{2+}$ transients are not observed until the L4.9 stage, when the anterior and posterior vm2 muscle arms complete a Notch-dependent lateral extension around the primary vulval epithelial cells ( $\mathrm{Li}$ et al., 2013). We did not observe $\mathrm{Ca}^{2+}$ transients in the VC neurons and uv1 cells except in egg- laying adults (data not shown), suggesting that activity in these cells does not contribute to circuit development. In adults, the juvenile HSN and vulval muscle activity disappears, leading to the establishment of characteristic "inactive" states in which adult animals spend $\sim 85 \%$ of their time. Inactive state activity closely resembles that seen in sterilized animals that do not accumulate any eggs. Figure 10 shows a working model for how postsynaptic muscle activity could promote burst firing in the presynaptic HSNs. We propose that uterine cells depress or excite the vulval muscles depending on the degree of stretch. Activation of the uterine muscles, which make gap junctions onto the vm2 muscles, would increase vulval muscle sensitivity to serotonin and other neurotransmitters released from HSN, which subsequently allows for rhythmic acetylcholine input from the VA/VB locomotion motor neurons to drive vulval muscle twitching contractions. Coordinated $\mathrm{Ca}^{2+}$ activity in the anterior and posterior vulval muscles diffuses into the vm 2 muscle arms to restimulate the HSNs and prolong the egg-laying active state. VC activity is coincident with strong vulval muscle contractions, whereas uv1 activity follows the passage of eggs through the vulva. Once sufficient eggs have been laid, excitatory feedback into the vulval muscles and back to the HSNs is reduced, increasing the probability that inhibitory acetylcholine, tyramine, and neuropeptides released from VC and uv1 will block subsequent HSN Ca ${ }^{2+}$ transients, returning the circuit to the inactive state.

Changes in gene expression likely contribute to the changes in circuit activity patterns that we observed between L4s and adults. Previous work has found that serotonin expression is low in L4 and increases as animals increase egg laying (Desai et al., 1988). Because mutants lacking serotonin have little effect on the timing of the first egg-laying event, we anticipate that other neurotransmitters released from the HSNs promote egg laying in young adults. KCC-2 and ABTS-1, two $\mathrm{Cl}^{-}$extruders required for inhibitory neurotransmission, show a developmental increase in HSN expression from L4 to adult (Tanis et al., 2009; Bellemer et al., 2011) that may be associated with the disappearance of spontaneous rhythmic activity in the HSNs after the late L4 stages. At the same time, we found that inhibitory ERG $\mathrm{K}^{+}$channel expression becomes upregulated in the vulval muscles of young adults. Studies in vertebrate models have shown that mechanical stretch can increase the transcription of receptors that enhance muscle contraction during parturition (Terzidou et al., 2005; Shynlova et al., 2007). We speculate that similar mechanisms may operate in the C. elegans reproductive system to drive expression of receptors and channels that modulate vulval muscle sensitivity to presynaptic input. Identifying additional genes with expression that in- 


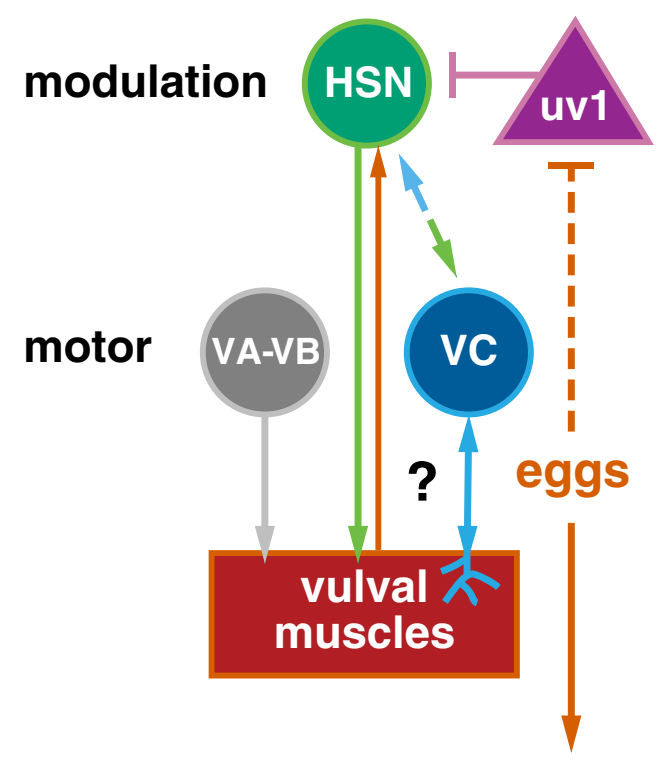

Figure 10. Working model of how retrograde signals from the postsynaptic vulval muscles (question mark) might modulate, directly or indirectly, burst firing in the presynaptic HSNs. HSN is a serotonergic and peptidergic modulatory command motor neuron that synapses onto the vulval muscles and the VC motor neurons. VA, VB, and VC are cholinergic motor neurons that synapse onto the vulval muscles; uv1 is a tyraminergic and peptidergic neuroendocrine cell mechanically activated by egg release that then feedback inhibits HSN. Arrows indicate activation and bar-headed lines indicate inhibition. See text for more details.

creases upon egg accumulation could help to explain how HSNdeficient animals are still able to enter otherwise normal egglaying active states after sufficient eggs have accumulated.

The HSNs show dramatic changes in $\mathrm{Ca}^{2+}$ transient frequency between the inactive and active states. Major G-proteins, $\mathrm{G} \alpha_{\mathrm{q}}$ and $\mathrm{G} \alpha_{\mathrm{o}}$, signal in HSN to increase and inhibit egg laying, respectively (Ringstad and Horvitz, 2008; Tanis et al., 2008). G-protein signaling in HSN may modulate an intrinsic pacemaker activity, similar to that seen in other central pattern generator circuits and in the cardiac pacemaker (Hille, 2001). G $\alpha_{\mathrm{o}}$ signaling in $\mathrm{HSN}$ activates inhibitory IRK $\mathrm{K}^{+}$channels (Emtage et al., 2012) and recent work has identified the T-type $\mathrm{Ca}^{2+}$ channel, CCA-1, and the $\mathrm{Na}^{+}$leak channels NCA-1 and NCA-2 as possible targets of excitatory $\mathrm{G} \alpha_{\mathrm{q}}$ signaling (Yeh et al., 2008; Topalidou et al., 2012; Zang et al., 2017). The balance of both G-protein signaling pathways would allow for HSN frequency modulation and dictate whether animals enter or leave the egglaying active state.

Early vulval muscle activity may be spontaneous or driven by neuronal input. Spontaneous $\mathrm{Ca}^{2+}$ transients promote the maturation of activity in many other cells (Moody and Bosma, 2005). We observed no change in behavioral onset or egg-laying rate in animals in which neuron or vulval muscle activity was silenced in the L4 stage. Although this may result from incomplete silencing using the HisCl-based approach, previous results in other circuits indicate that synapse development does not require $\mathrm{Ca}^{2+}$ dependent excitatory transmission (Verhage et al., 2000; Lu et al., 2013; Sando et al., 2017). Although G-protein signaling may drive early $\mathrm{Ca}^{2+}$ activity in the absence of electrical activity, synaptic transmission would still require $\mathrm{Ca}^{2+}$-dependent vesicle fusion. The persistence of vulval muscle activity in animals that lack HSNs and its recovery after acute neural silencing suggests that the activity that we observed arises from a shared mechanism that is not strictly required for synapse development and/or recovers quickly after histamine washout.
Our work shows the functional importance of the postsynaptic vm 2 muscle arms in coordinating muscle activity during egglaying behavior. Because of the intervening vulval slit through which eggs are laid, the vm2 muscle arms are the only sites of contact between the anterior and posterior muscles. Coordinated muscle $\mathrm{Ca}^{2+}$ transients appear during the L4.9 larval stage after vm 2 muscle arm development. After development, the vm 2 muscle arms may be electrically coupled at their points of contact, allowing for the immediate spread of electrical activity and/or $\mathrm{Ca}^{2+}$ signals between the anterior and posterior muscles. In addition to uncoordinated $\mathrm{vm} 1$ and $\mathrm{vm} 2 \mathrm{Ca}^{2+}$ activity, mutants missing the vm 2 muscle arms do not show regenerative HSN $\mathrm{Ca}^{2+}$ activity, resembling the consequences of vulval muscle electrical silencing (Li et al., 2013). The vm2 muscle arms also form the sites of synaptic input from HSN and VC. We have shown previously that the ERG $\mathrm{K}^{+}$channel and SER-1 serotonin receptor localize to the vm2 muscle arm region (Collins and Koelle, 2013; Li et al., 2013). Both ERG and SER-1 have C-terminal PDZ interaction motifs and SER-1 has been shown to interact with the large PDZ scaffold protein MPZ-1, which may drive the local organization of these and other molecules to the vm2 muscle arms (Xiao et al., 2006). Innexin gap junction proteins, which are potential targets of G-protein signaling (Correa et al., 2015), may also play a role in driving the development of coordinated vulval muscle contractility and HSN "burst" activity in the circuit during egg laying.

The importance of stretch-mediated feedback is well characterized in circuits that control autonomic functions (Dethier and Gelperin, 1967; Gelperin, 1971; Spencer et al., 2002), the rhythmic uterine activity during parturition (Ferguson's reflex) (Ferguson, 1941), and in circuits which generate rhythmic motor outputs (Grillner, 2003; Marder et al., 2005; Blitz and Nusbaum, 2011). Stretch can provide either positive or negative feedback to downstream reflex and homeostatic circuits. For example, specialized mechanosensory neurons activated by gastric stretch induce satiety by providing negative feedback to neural circuits controlling food consumption (Dethier and Gelperin, 1967; Zagorodnyuk et al., 2001). In guinea pigs, stretch-sensitive interneurons provide ascending excitatory and descending inhibitory inputs to generate peristaltic neural reflexes in the distal colon (Spencer and Smith, 2004). Mechanical stretch (from egg accumulation) or artificially induced distension of the reproductive tract in female flies induces an attraction to acetic acid so that eggs can be laid in optimal environments (Gou et al., 2014). In the cases described above, how stretch sensory inputs modulate the activity of neural circuits and synaptic transmission is not always clear.

The C. elegans egg-laying homeostat is regulated by egg accumulation that sustains rhythmic activity in a motor neuron for muscle contraction and egg release. In the case of the Ferguson's parturition reflex, initial stretch-induced myogenic contractions engage the neuroendocrine feed-forward loop, similar to our results showing that vulval muscle activity promotes a feed-forward increase in HSN activity. Does mechanosensory stretch also play a role in the feedback inhibition of C. elegans egg laying? Although the release of eggs and the loss of uterine stretch should decrease feed-forward drive into the vulval muscles and HSN, additional mechanical feedback from the VC motor neurons and the uv1 neuroendocrine cells may be required to exit the active state completely. $\mathrm{VC} \mathrm{Ca}^{2+}$ activity is coincident with egg release and mutants with reduced acetylcholine or VC function have more frequent egg-laying events (Bany et al., 2003). The uv1 cells are 
mechanically deformed and activated by egg release and tyramine and inhibitory neuropeptides released from uv1 inhibit HSN activity (Collins et al., 2016; Banerjee et al., 2017). Further studies of the C. elegans egg-laying homeostat described here should allow the determination of conserved molecular, cellular, and synaptic mechanisms that drive stretch-dependent feedback.

\section{References}

Adler CE, Fetter RD, Bargmann CI (2006) UNC-6/Netrin induces neuronal asymmetry and defines the site of axon formation. Nat Neurosci 9:511518. CrossRef Medline

Akerboom J, Carreras Calderón N, Tian L, Wabnig S, Prigge M, Tolö J, Gordus A, Orger MB, Severi KE, Macklin JJ, Patel R, Pulver SR, Wardill TJ, Fischer E, Schüler C, Chen TW, Sarkisyan KS, Marvin JS, Bargmann CI, Kim DS, et al. (2013) Genetically encoded calcium indicators for multi-color neural activity imaging and combination with optogenetics. Front Mol Neurosci 6:2. CrossRef Medline

Banerjee N, Bhattacharya R, Gorczyca M, Collins KM, Francis MM (2017) Local neuropeptide signaling modulates serotonergic transmission to shape the temporal organization of C. elegans egg-laying behavior. PLoS Genet 13:e1006697. CrossRef Medline

Bany IA, Dong MQ, Koelle MR (2003) Genetic and cellular basis for acetylcholine inhibition of Caenorhabditis elegans egg-laying behavior. J Neurosci 23:8060-8069. CrossRef Medline

Bellemer A, Hirata T, Romero MF, Koelle MR (2011) Two types of chloride transporters are required for $\mathrm{GABA}(\mathrm{A})$ receptor-mediated inhibition in C. elegans. EMBO J 30:1852-1863. CrossRef Medline

Blitz DM, Nusbaum MP (2011) Neural circuit flexibility in a small sensorimotor system. Curr Opin Neurobiol 21:544-552. CrossRef Medline

Borodinsky LN, Root CM, Cronin JA, Sann SB, Gu X, Spitzer NC (2004) Activity-dependent homeostatic specification of transmitter expression in embryonic neurons. Nature 429:523-530. CrossRef Medline

Brenner S (1974) The genetics of Caenorhabditis elegans. Genetics 77:71-94. Medline

Burdine RD, Chen EB, Kwok SF, Stern MJ (1997) egl-17 encodes an invertebrate fibroblast growth factor family member required specifically for sex myoblast migration in Caenorhabditis elegans. Proc Natl Acad Sci U S A 94:2433-2437. CrossRef Medline

Burdine RD, Branda CS, Stern MJ (1998) EGL-17(FGF) expression coordinates the attraction of the migrating sex myoblasts with vulval induction in C. elegans. Development 125:1083-1093. Medline

Cai T, Fukushige T, Notkins AL, Krause M (2004) Insulinoma-associated protein IA-2, a vesicle transmembrane protein, genetically interacts with UNC-31/CAPS and affects neurosecretion in Caenorhabditis elegans. J Neurosci 24:3115-3124. CrossRef Medline

Carnell L, Illi J, Hong SW, McIntire SL (2005) The G-protein-coupled serotonin receptor SER-1 regulates egg laying and male mating behaviors in Caenorhabditis elegans. J Neurosci 25:10671-10681. CrossRef Medline

Chase DL, Pepper JS, Koelle MR (2004) Mechanism of extrasynaptic dopamine signaling in Caenorhabditis elegans. Nat Neurosci 7:1096-1103. CrossRef Medline

Clark SG, Lu X, Horvitz HR (1994) The Caenorhabditis elegans locus lin-15, a negative regulator of a tyrosine kinase signaling pathway, encodes two different proteins. Genetics 137:987-997. Medline

Colavita A, Tessier-Lavigne M (2003) A neurexin-related protein, BAM-2, terminates axonal branches in C. elegans Science 302:293-296. CrossRef Medline

Collins KM, Koelle MR (2013) Postsynaptic ERG potassium channels limit muscle excitability to allow distinct egg-laying behavior states in Caenorhabditis elegans. J Neurosci 33:761-775. CrossRef Medline

Collins KM, Bode A, Fernandez RW, Tanis JE, Brewer JC, Creamer MS, Koelle MR (2016) Activity of the C. elegans egg-laying behavior circuit is controlled by competing activation and feedback inhibition. Elife 5:e21126. CrossRef Medline

Correa PA, Gruninger T, García LR (2015) DOP-2 D2-like receptor regulates UNC-7 innexins to attenuate recurrent sensory motor neurons during C. elegans copulation. J Neurosci 35:9990-10004. CrossRef Medline

Dempsey CM, Mackenzie SM, Gargus A, Blanco G, Sze JY (2005) Serotonin (5HT), fluoxetine, imipramine and dopamine target distinct 5HT receptor signaling to modulate Caenorhabditis elegans egg-laying behavior. Genetics 169:1425-1436. CrossRef Medline

Desai C, Garriga G, McIntire SL, Horvitz HR (1988) A genetic pathway for the development of the Caenorhabditis elegans HSN motor neurons. Nature 336:638-646. CrossRef Medline

Dethier VG, Gelperin A (1967) Hyperphagia in the blowfly. J Exp Biol 47:191-200.

Emtage L, Aziz-Zaman S, Padovan-Merhar O, Horvitz HR, Fang-Yen C, Ringstad N (2012) IRK-1 potassium channels mediate peptidergic inhibition of Caenorhabditis elegans serotonin neurons via a $G(o)$ signaling pathway. J Neurosci 32:16285-16295. CrossRef Medline

Feinberg EH, Vanhoven MK, Bendesky A, Wang G, Fetter RD, Shen K, Bargmann CI (2008) GFP reconstitution across synaptic partners (GRASP) defines cell contacts and synapses in living nervous systems. Neuron 57: 353-363. CrossRef Medline

Ferguson JKW (1941) A study of the motility of the intact uterus at term. Surg Gynaecol Obste. 73:359-366.

Flavell SW, Pokala N, Macosko EZ, Albrecht DR, Larsch J, Bargmann CI (2013) Serotonin and the neuropeptide PDF initiate and extend opposing behavioral states in C. elegans. Cell 154:1023-1035. CrossRef Medline

Fujiwara M, Aoyama I, Hino T, Teramoto T, Ishihara T (2016) Gonadal maturation changes chemotaxis behavior and neural processing in the olfactory circuit of Caenorhabditis elegans. Curr Biol 26:1522-1531. CrossRef Medline

Garaschuk O, Hanse E, Konnerth A (1998) Developmental profile and synaptic origin of early network oscillations in the CA1 region of rat neonatal hippocampus. J Physiol 507:219-236. CrossRef Medline

Garaschuk O, Linn J, Eilers J, Konnerth A (2000) Large-scale oscillatory calcium waves in the immature cortex. Nat Neurosci 3:452-459. CrossRef Medline

Gelperin A (1971) Abdominal sensory neurons providing negative feedback to the feeding behavior of the blowfly. Zeitschrift fur vergleichende Physiologie 72:17-31. CrossRef

Gou B, Liu Y, Guntur AR, Stern U, Yang CH (2014) Mechanosensitive neurons on the internal reproductive tract contribute to egg-laying-induced acetic acid attraction in drosophila. Cell Rep 9:522-530. CrossRef Medline

Grillner S (2003) The motor infrastructure: from ion channels to neuronal networks. Nat Rev Neurosci 4:573-586. CrossRef Medline

Gu X, Spitzer NC (1995) Distinct aspects of neuronal differentiation encoded by frequency of spontaneous $\mathrm{Ca}^{2+}$ transients. Nature 375:784787. CrossRef Medline

Gu X, Olson EC, Spitzer NC (1994) Spontaneous neuronal calcium spikes and waves during early differentiation. J Neurosci 14:6325-6335. CrossRef Medline

Gürel G, Gustafson MA, Pepper JS, Horvitz HR, Koelle MR (2012) Receptors and other signaling proteins required for serotonin control of locomotion in Caenorhabditis elegans. Genetics 192:1359-1371. CrossRef Medline

Hanson MG, Milner LD, Landmesser LT (2008) Spontaneous rhythmic activity in early chick spinal cord influences distinct motor axon pathfinding decisions. Brain Res Rev 57:77-85. CrossRef Medline

Hapiak VM, Hobson RJ, Hughes L, Smith K, Harris G, Condon C, Komuniecki P, Komuniecki RW (2009) Dual excitatory and inhibitory serotonergic inputs modulate egg laying in Caenorhabditis elegans. Genetics 181:153-163. CrossRef Medline

Hardaker LA, Singer E, Kerr R, Zhou G, Schafer WR (2001) Serotonin modulates locomotory behavior and coordinates egg-laying and movement in Caenorhabditis elegans. J Neurobiol 49:303-313. CrossRef Medline

Harfe BD, Fire A (1998) Muscle and nerve-specific regulation of a novel NK-2 class homeodomain factor in Caenorhabditis elegans. Development 125:421-429. Medline

Hille B (2001) Ion channels of excitable membranes, Ed 3. Sunderland, MA: Sinaur.

Hobson RJ, Hapiak VM, Xiao H, Buehrer KL, Komuniecki PR, Komuniecki RW (2006) SER-7, a Caenorhabditis elegans 5-HT7-like receptor, is essential for the 5-HT stimulation of pharyngeal pumping and egg laying. Genetics 172:159-169. CrossRef Medline

Jarecki J, Keshishian H (1995) Role of neural activity during synaptogenesis in Drosophila. J Neurosci 15:8177-8190. CrossRef Medline

Li C, Chalfie M (1990) Organogenesis in C. elegans: positioning of neurons and muscles in the egg-laying system. Neuron 4:681-695. CrossRef Medline

Li P, Collins KM, Koelle MR, Shen K (2013) LIN-12/Notch signaling instructs postsynaptic muscle arm development by regulating UNC-40/ 
DCC and MADD-2 in Caenorhabditis elegans. Elife 2:e00378. CrossRef Medline

Lu W, Bushong EA, Shih TP, Ellisman MH, Nicoll RA (2013) The cellautonomous role of excitatory synaptic transmission in the regulation of neuronal structure and function. Neuron 78:433-439. CrossRef Medline

Marder E, Bucher D, Schulz DJ, Taylor AL (2005) Invertebrate central pattern generation moves along. Curr Biol 15:R685-R699. CrossRef Medline

Mok DZ, Sternberg PW, Inoue T (2015) Morphologically defined substages of C. elegans vulval development in the fourth larval stage. BMC Dev Biol 15:26. CrossRef Medline

Moody WJ, Bosma MM (2005) Ion channel development, spontaneous activity, and activity-dependent development in nerve and muscle cells. Physiol Rev 85:883-941. CrossRef Medline

Moresco JJ, Koelle MR (2004) Activation of EGL-47, a Galpha(o)-coupled receptor, inhibits function of hermaphrodite-specific motor neurons to regulate Caenorhabditis elegans egg-laying behavior. J Neurosci 24:85228530. CrossRef Medline

Newman AP, White JG, Sternberg PW (1996) Morphogenesis of the C. elegans hermaphrodite uterus. Development 122:3617-3626. Medline

Patel MR, Lehrman EK, Poon VY, Crump JG, Zhen M, Bargmann CI, Shen K (2006) Hierarchical assembly of presynaptic components in defined $C$. elegans synapses. Nat Neurosci 9:1488-1498. CrossRef Medline

Pokala N, Liu Q, Gordus A, Bargmann CI (2014) Inducible and titratable silencing of Caenorhabditis elegans neurons in vivo with histamine-gated chloride channels. Proc Natl Acad Sci U S A 111:2770-2775. CrossRef Medline

Raizen DM, Zimmerman JE, Maycock MH, Ta UD, You YJ, Sundaram MV, Pack AI (2008) Lethargus is a Caenorhabditis elegans sleep-like state. Nature 451:569-572. CrossRef Medline

Ravi B, Nassar LM, Kopchock III RJ, Dhakal P, Scheetz M, Collins KM (2018) Ratiometric calcium imaging of individual neurons in behaving Caerhabditis elegans. J Vis Exp 132:e56911. CrossRef Medline

Ringstad N, Horvitz HR (2008) FMRFamide neuropeptides and acetylcholine synergistically inhibit egg-laying by C. elegans. Nat Neurosci 11 : 1168-1176. CrossRef Medline

Sando R, Bushong E, Zhu Y, Huang M, Considine C, Phan S, Ju S, Uytiepo M, Ellisman M, Maximov A (2017) Assembly of excitatory synapses in the absence of glutamatergic neurotransmission. Neuron 94:312-321.e3. CrossRef Medline

Schindelin J, Arganda-Carreras I, Frise E, Kaynig V, Longair M, Pietzsch T, Preibisch S, Rueden C, Saalfeld S, Schmid B, Tinevez JY, White DJ, Hartenstein V, Eliceiri K, Tomancak P, Cardona A (2012) Fiji: an opensource platform for biological-image analysis. Nat Methods 9:676-682. CrossRef Medline

Shen K, Bargmann CI (2003) The immunoglobulin superfamily protein SYG-1 determines the location of specific synapses in C. elegans. Cell 112:619-630. CrossRef Medline

Shen K, Fetter RD, Bargmann CI (2004) Synaptic specificity is generated by the synaptic guidepost protein SYG-2 and its receptor, SYG-1. Cell 116: 869-881. CrossRef Medline

Shynlova O, Williams SJ, Draper H, White BG, MacPhee DJ, Lye SJ (2007) Uterine stretch regulates temporal and spatial expression of fibronectin protein and its alpha 5 integrin receptor in myometrium of unilaterally pregnant rats. Biol Reprod 77:880-888. CrossRef Medline

Spencer NJ, Smith TK (2004) Mechanosensory S-neurons rather than AHneurons appear to generate a rhythmic motor pattern in guinea-pig distal colon. J Physiol 558:577-596. CrossRef Medline

Spencer NJ, Hennig GW, Smith TK (2002) A rhythmic motor pattern activated by circumferential stretch in guinea-pig distal colon. J Physiol 545: 629-648. CrossRef Medline

Sulston JE, Horvitz HR (1977) Post-embryonic cell lineages of the nematode, Caenorhabditis elegans. Dev Biol 56:110-156. CrossRef Medline
Sundaram M, Greenwald I (1993) Suppressors of a lin-12 hypomorph define genes that interact with both lin-12 and glp-1 in Caenorhabditis elegans. Genetics 135:765-783. Medline

Tanis JE, Moresco JJ, Lindquist RA, Koelle MR (2008) Regulation of serotonin biosynthesis by the $\mathrm{G}$ proteins galphao and galphaq controls serotonin signaling in Caenorhabditis elegans. Genetics 178:157-169. CrossRef Medline

Tanis JE, Bellemer A, Moresco JJ, Forbush B, Koelle MR (2009) The potassium chloride cotransporter KCC-2 coordinates development of inhibitory neurotransmission and synapse structure in Caenorhabditis elegans. J Neurosci 29:9943-9954. CrossRef Medline

Terzidou V, Sooranna SR, Kim LU, Thornton S, Bennett PR, Johnson MR (2005) Mechanical stretch up-regulates the human oxytocin receptor in primary human uterine myocytes. J Clin Endocrinol Metab 90:237-246. CrossRef Medline

Topalidou I, Keller C, Kalebic N, Nguyen KC, Somhegyi H, Politi KA, Heppenstall P, Hall DH, Chalfie M (2012) Genetically separable functions of the MEC-17 tubulin acetyltransferase affect microtubule organization. Curr Biol 22:1057-1065. CrossRef Medline

Tsalik EL, Hobert O (2003) Functional mapping of neurons that control locomotory behavior in Caenorhabditis elegans. J Neurobiol 56:178-197. CrossRef Medline

Verhage M, Maia AS, Plomp JJ, Brussaard AB, Heeroma JH, Vermeer H, Toonen RF, Hammer RE, van den Berg TK, Missler M, Geuze HJ, Südhof TC (2000) Synaptic assembly of the brain in the absence of neurotransmitter secretion. Science 287:864-869. CrossRef Medline

Waggoner LE, Zhou GT, Schafer RW, Schafer WR (1998) Control of alternative behavioral states by serotonin in Caenorhabditis elegans. Neuron 21:203-214. CrossRef Medline

Warp E, Agarwal G, Wyart C, Friedmann D, Oldfield CS, Conner A, Del Bene F, Arrenberg AB, Baier H, Isacoff EY (2012) Emergence of patterned activity in the developing zebrafish spinal cord. Curr Biol 22:93-102. CrossRef Medline

Watt AJ, Cuntz H, Mori M, Nusser Z, Sjöström PJ, Häusser M (2009) Traveling waves in developing cerebellar cortex mediated by asymmetrical purkinje cell connectivity. Nat Neurosci 12:463-473. CrossRef Medline

White JG, Southgate E, Thomson JN, Brenner S (1986) The structure of the nervous system of the nematode Caenorhabditis elegans. Philos Trans R Soc Lond B Biol Sci 314:1-340. CrossRef Medline

Wong RO, Chernjavsky A, Smith SJ, Shatz CJ (1995) Early functional neural networks in the developing retina. Nature 374:716-718. CrossRef Medline

Xiao H, Hapiak VM, Smith KA, Lin L, Hobson RJ, Plenefisch J, Komuniecki R (2006) SER-1, a Caenorhabditis elegans 5-HT2-like receptor, and a multi-PDZ domain containing protein (MPZ-1) interact in vulval muscle to facilitate serotonin-stimulated egg-laying. Dev Biol 298:379-391. CrossRef Medline

Yeh E, Ng S, Zhang M, Bouhours M, Wang Y, Wang M, Hung W, Aoyagi K, Melnik-Martinez K, Li M, Liu F, Schafer WR, Zhen M (2008) A putative cation channel, NCA-1, and a novel protein, UNC-80, transmit neuronal activity in C. elegans. PLoS Biol 6:e55. CrossRef Medline

Zagorodnyuk VP, Chen BN, Brookes SJ (2001) Intraganglionic laminar endings are mechano-transduction sites of vagal tension receptors in the guinea-pig stomach. J Physiol 534:255-268. CrossRef Medline

Zang KE, Ho E, Ringstad N (2017) Inhibitory peptidergic modulation of $C$. elegans serotonin neurons is gated by T-type calcium channels. Elife 6:e22771. CrossRef Medline

Zhang M, Chung SH, Fang-Yen C, Craig C, Kerr RA, Suzuki H, Samuel AD, Mazur E, Schafer WR (2008) A self-regulating feed-forward circuit controlling C. elegans egg-laying behavior. Curr Biol 18:1445-1455. CrossRef Medline 